\title{
DIGITALCOMMONS
}

$@$ WAYNESTATE -

Wayne State University

Wayne State University Dissertations

$1-1-2017$

\section{Adolescent Achievement: Relative Contributions Of Social Emotional Learning, Self-Efficacy And Microsystem Supports}

Meghan Elizabeth Fairless

Wayne State University,

Follow this and additional works at: https://digitalcommons.wayne.edu/oa_dissertations

Part of the Educational Psychology Commons

\section{Recommended Citation}

Fairless, Meghan Elizabeth, "Adolescent Achievement: Relative Contributions Of Social Emotional Learning, Self-Efficacy And Microsystem Supports" (2017). Wayne State University Dissertations. 1699.

https://digitalcommons.wayne.edu/oa_dissertations/1699

This Open Access Dissertation is brought to you for free and open access by DigitalCommons@WayneState. It has been accepted for inclusion in Wayne State University Dissertations by an authorized administrator of DigitalCommons@WayneState. 
ADOLESCENT ACHIEVEMENT: RELATIVE CONTRIBUTIONS OF SOCIAL EMOTIONAL LEARNING, SELF-EFFICACY AND MICROSYSTEM SUPPORTS

by

\author{
MEGHAN ELIZABETH FAIRLESS \\ DISSERTATION \\ Submitted to the Graduate School \\ of Wayne State University, \\ Detroit, Michigan \\ in partial fulfillment of the requirements \\ for the degree of \\ DOCTOR OF PHILOSOPHY
}

2017

MAJOR: EDUCATIONAL PSYCHOLOGY

Approved By:

Advisor

Date 
(C) COPYRIGHT BY

\section{MEGHAN ELIZABETH FAIRLESS}

2017

All Rights Reserved 


\section{DEDICATION}

To my incredible family - my parents, Kent and Cindy Fairless, my sister, Jessica, my brother Drew, my brother-in-law Andrew, my nephew Patrick, and my boyfriend Zachary Lewis. Words cannot begin to express how grateful I am for your unconditional love and support throughout this program. I am blessed to be on the receiving end of your continuous encouragement. Your belief and confidence in my ability to complete this project was the motivation I needed.

Love you all the most. 


\section{ACKNOWLEDGEMENTS}

Completing this project has been the most difficult task I have personally taken on. While the past four years within the doctorate program have challenged me with studying for and passing the qualifying examinations, obtaining my clinical internship hours, and writing countless papers, none have been as daunting as the dissertation. I want to express my sincere gratitude to those who helped me through the arduous and rewarding process, including my professors, family, friends and colleagues. This would not have been possible without your unwavering support.

To begin with, to my academic advisor, Dr. Cheryl Somers, an enormous thank you for your constant support. You have provided me with endless guidance and encouragement throughout this process. I am so thankful for the patience and knowledge you shared with me over the course of developing, writing and finalizing this project. You have helped shape the educational psychologist I have become throughout my time at Wayne State University. Your work ethic, perseverance and ability to get things done, no doubt greatly contributed to my ability to finish this program; you truly inspire me. Your belief in my abilities helped me to believe in my own capabilities.

I would also like to extend sincere gratitude to the other professors who guided me in this process. To Dr. Francesca Pernice, thank you for introducing me to the true art of therapy. I will always appreciate your passion and zest for this field, as well as your kind and genuine character. To Dr. Doug Barnett, I want to thank you for everything you have taught me throughout my internships at the General Pediatric Adolescent Medicine Clinic. I am so grateful to have had the opportunity to develop my clinical skills with the wonderful staff and patients at GPAM. Your unconditional support over the past few years has been paramount to my continuation of developing and honing my skill set as a practitioner. Thank you for believing in me and 
encouraging me to be the best therapist. To Dr. Barry Markman, thank you for your assistance and advice. I will fondly remember your classroom jokes and reinforcement. Last but certainly not least, I would like to thank Dr. Jina Yoon. Even from afar, your encouragement and support has been sensed. I am so appreciative of the time I spent with you at Wayne State. You demonstrate a remarkable blend of being an excellent educator as well as practitioner.

To Principal Jason Riggs and the students and families of Waterford School District. I would like to thank you all for allowing me to conduct my research at Mott High School. Without your support and assistance, this project would not have been possible. Thank you to the wonderful staff members who helped coordinate the date and times of data collection as well.

In addition, I would like to thank my family and friends. To my parents, sister, brother, brother-in-law, nephew and boyfriend, I cannot thank you enough. You all have provided me with unconditional love and support throughout this entire program. I am so blessed to have such kind and loyal individuals in my life. The endless phone calls, texts, and words and displays of encouragement were tremendous in helping me pursue a dream. To my grandparents, aunts, uncles and cousins who never doubted my success. A tremendous thank you to the classmates in my doctorate cohort. I honestly do not think I would have survived the last four years without your kindness and support. Our group texts seriously got me through some self-doubt! To my amazing friends, thank you for the continuous support, not only in my educational career but life in general. I will forever remember the kindness and love I received from all in my journey throughout the doctoral in educational psychology program at Wayne State University. Thank you. 


\section{TABLE OF CONTENTS}

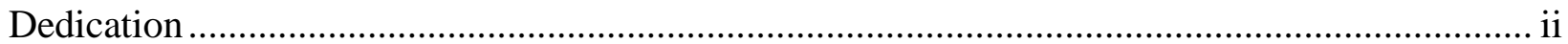

Acknowledgements ......................................................................................................

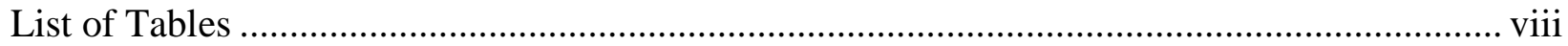

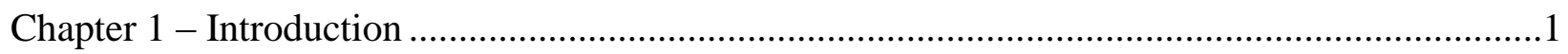

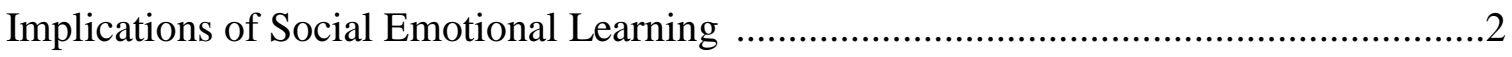

Ecological Systems Perspective...................................................................................

Intrapersonal Factors...........................................................................................6

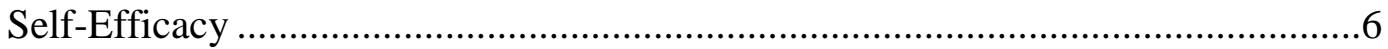

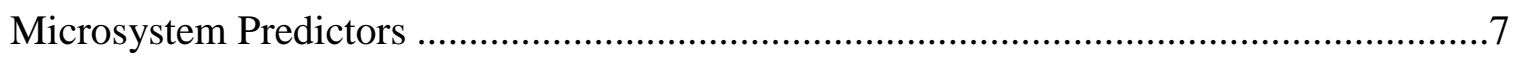

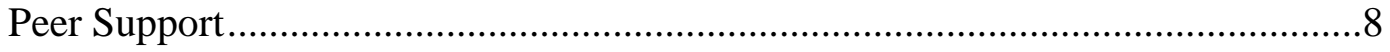

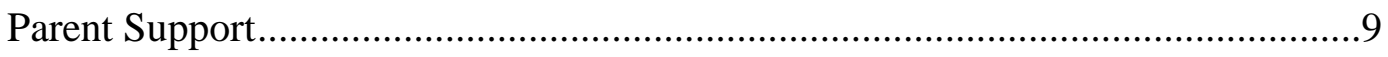

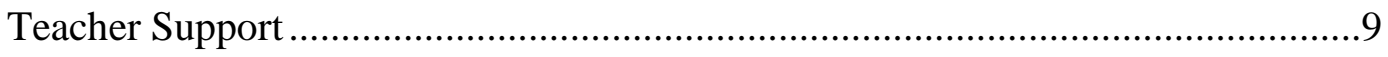

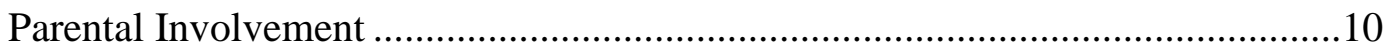

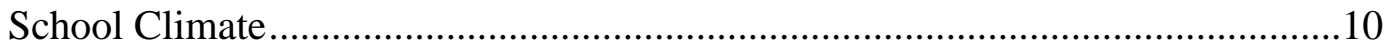

Limitations of Prior Research and Purpose of Proposed Study …….................................11

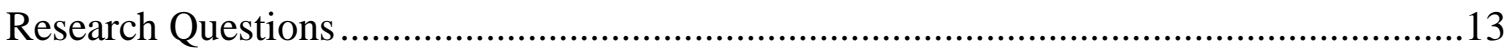

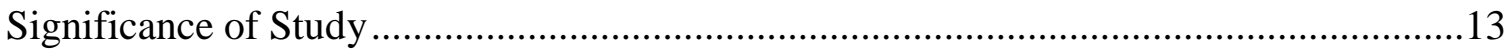

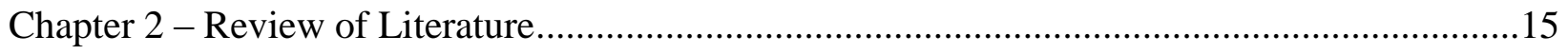

Impact of Social and Emotional Learning …………...................................................17

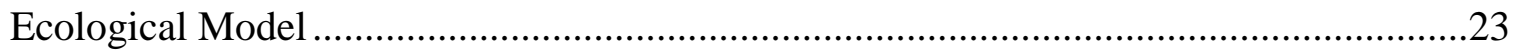

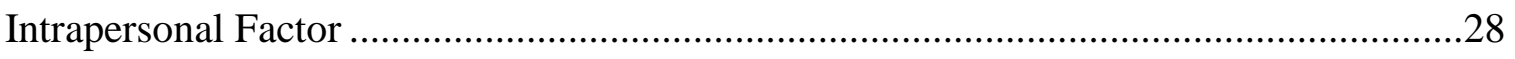

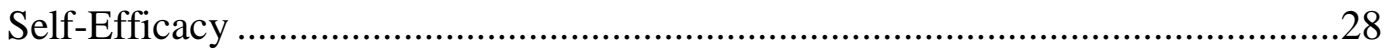




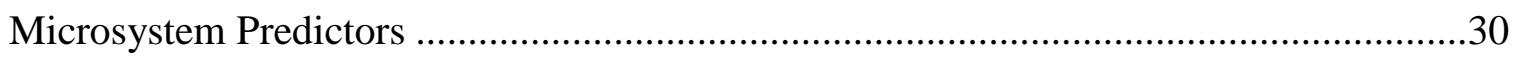

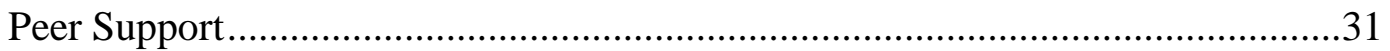

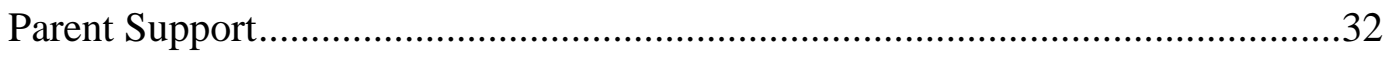

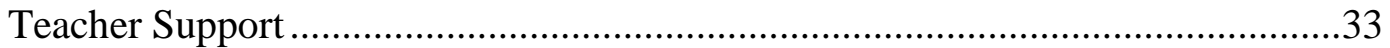

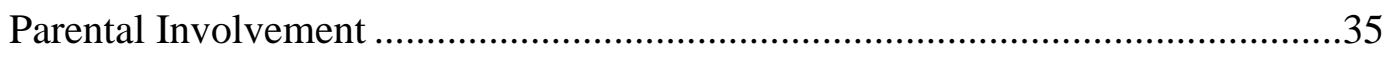

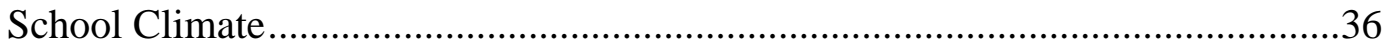

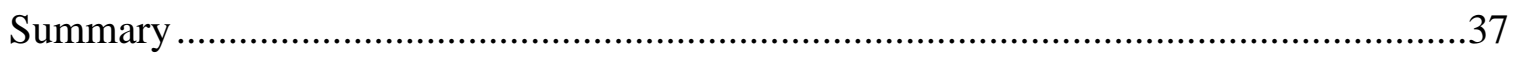

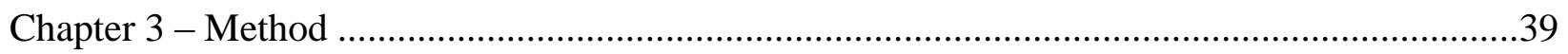

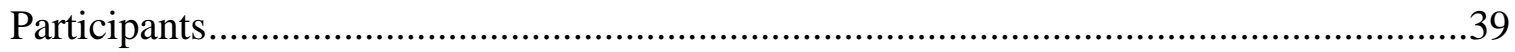

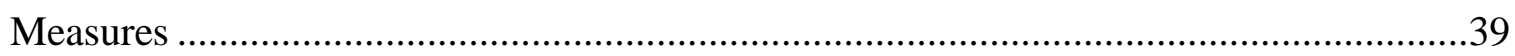

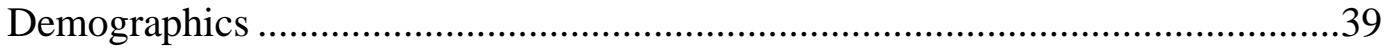

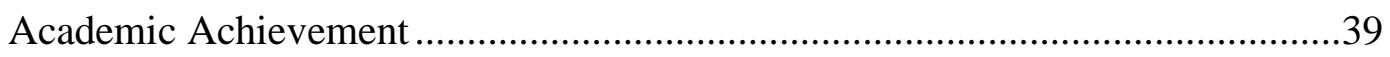

Social Emotional Learning .......................................................................40

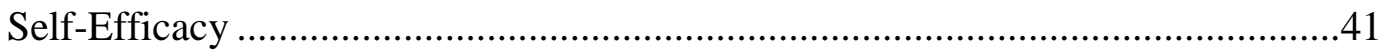

Peer, Parent \& Teacher Support.....................................................................42

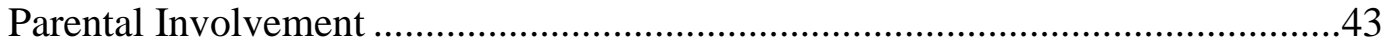

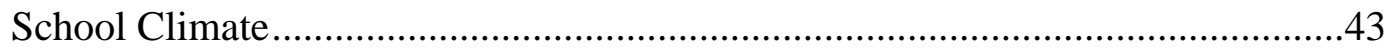

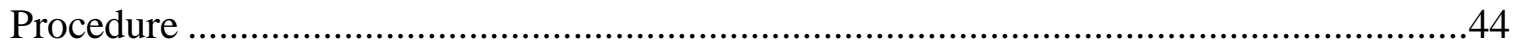

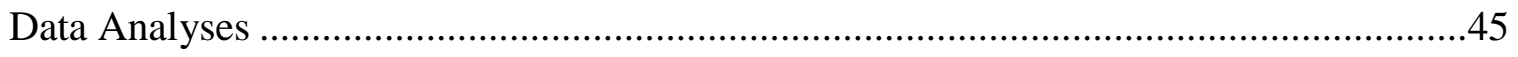

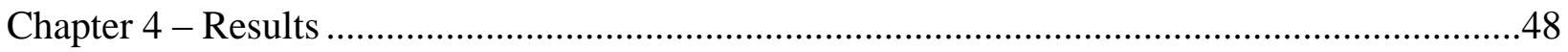

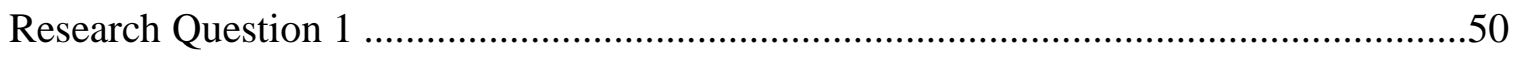

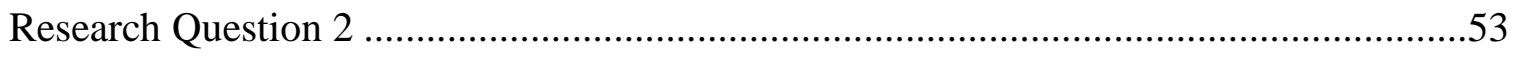

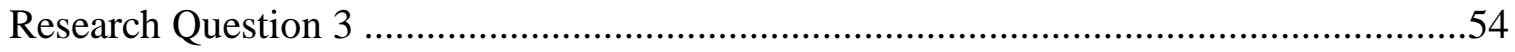




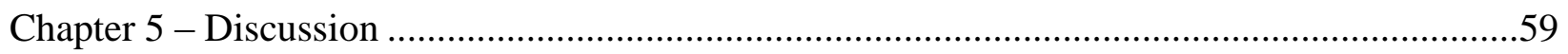

Limitations and Future Directions .................................................................63

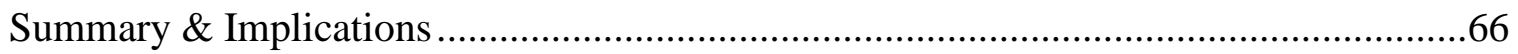

Appendix A: Letter of Support from Mott High School...................................................69

Appendix B: Human Investigation Committee Approval .................................................70

Appendix C: Parent Supplemental Information Letter ...................................................... 71

Appendix D: Administration Script ....................................................................... 73

Appendix E: Documentation of Adolescent Assent Forms .................................................74

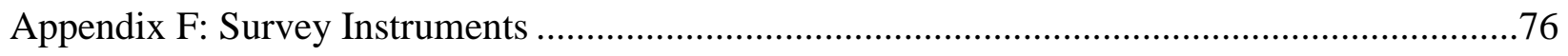

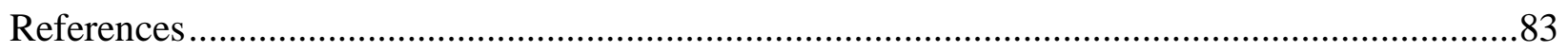

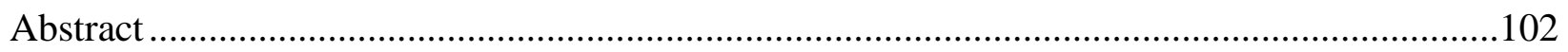

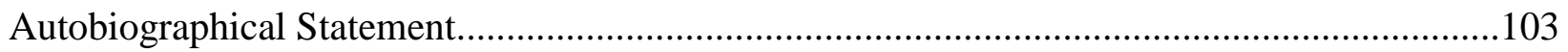




\section{LIST OF TABLES}

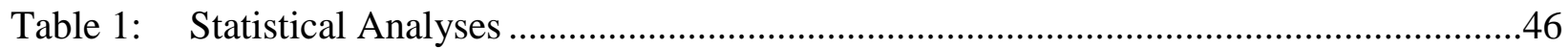

Table 2: Descriptive Statistics and Cronbach's Alphas: Survey Aggregate Score ...................49

Table 3: $\quad$ Pearson Product-Moment Correlation Matrix: All Study Variables..........................49

Table 4: Pearson's Product-Moment Correlation Matrix: Academic Achievement \& Social Emotional Learning and SEL Subscales ...........................................................51

Table 5: Pearson's Product-Moment Correlation Matrix: Class Specific Academic Achievement \& Social Emotional Learning and SEL Subscales

Table 6: Summary of Hierarchical Linear Regression Analysis for Variables Predicting Academic Achievement (Demographics and SEL)

Table 7: $\quad$ Summary of Hierarchical Linear Regression Analysis for Variables Predicting Academic Achievement (Demographics and Intrapersonal Variables)

Table 8: $\quad$ Summary of Hierarchical Linear Regression Analysis for Variables Predicting Academic Achievement (Demographics and Microsystem Variables)

Table 9: Summary of Hierarchical Linear Regression Analysis for Variables Predicting Academic Achievement (Demographics, Intrapersonal Variables, and Microsystem Variables) 


\section{CHAPTER 1 INTRODUCTION}

The topic of adolescent mental health is increasing in urgency, as more than 1 in 5 schoolaged children are now diagnosed with a mental health disorder (Tolan \& Dodge, 2005). According to Tolan and Dodge (2005) nearly $20 \%$ of students show signs and symptoms that meet Diagnostic and Statistical Manual of Mental Disorders (DSM) criteria. These symptoms have a clear impact on the social and emotional functioning of students. At the same time, there are large numbers of children with weak academic skill development. According to the National Assessment for Educational Progress (NAEP, 2015) students are struggling in all three of the main academic domains, including reading, writing, and mathematics. It is estimated that only about one third of students are scoring at or above Proficient in these subject areas, with the majority of students graduating high school without adequate skills. In the face of pressures of legislation demanding high levels of student proficiency, this has become clear and concerning. The intersection between social and emotional learning (SEL) and academic functioning in understanding academic skill development is of focus in the current study. Meta-analyses of SEL programs have found increased academic achievement as well as an indirect effect of reduction in mental health concerns (Neil \& Christensen, 2007; Durlak, Weissberg, Dymnicki, Taylor \& Schellinger, 2011). There is significant promise in implementing evidence-based SEL programs in the school setting.

Social and emotional skills are considered to be a vital part of a child's overall development (Weissberg, Walberg, O’Brien, \& Kuster, 2003; Weissberg, Durlak, Domitrovich, \& Gullotta, 2015). SEL can be identified as the way students think, feel, and behave in regards to themselves and others around them (Elias et al., 1997). These skills allow for more positive social interactions with others, as well as demonstrations of self-control, and understanding of emotions (Payton et al., 2000). SEL focuses on the development of youth through the promotion of specific cognitive, 
behavioral and affective competencies (Durlak et al., 2011). Ultimately, the goal of SEL is to enable students to demonstrate appropriate responses to a variety of environmental demands, whether positive or negative, as well as to take advantage of different opportunities presented. Rather than reacting in an external manner, students with more emotional competency are able to demonstrate a more developed internal loci of control. Students with appropriate SEL knowledge are able to recognize that they are capable of controlling their reactions in different situations, and handle themselves appropriately.

The Collaborative for Academic, Social and Emotional Learning (CASEL) is identified as developing one of the most well-recognized frameworks for SEL (Osher et al., 2016). According to CASEL (2015) there are five interrelated components of comprehensive SEL. The first focuses on self-awareness. Skills within this specific component include identifying emotions, promoting self-confidence and enhancing self-efficacy. Next, self-management, focuses on curbing impulse control, improving stress management and self-discipline. It also emphasizes motivation through goal setting and employing organizational skills. In addition, self-awareness is a component that incorporates specific skills such as perspective taking and empathy, appreciating diversity, and demonstrating respect for others. Relationship skills is another component identified by CASEL. This focuses on communication skills, increasing social engagement, developing cooperation and conflict resolution skills, and seeking and/or offering help. Lastly, responsible decision making is a component of SEL. Skills falling under this include teaching problem solving skills and developing ethical responsibilities. As highlighted, there are a variety of skills that fall under this umbrella-like term.

\section{Implications of Social and Emotional Learning}


A meta-analysis conducted by Sklad, Diekstra, Ritter, Ben, \& Gravesteijn (2012) identified the majority of intervention programs focused on improving social and emotional competencies resulted in seven categories of beneficial effects: social skills, antisocial behavior, mental health, substance abuse, academic achievement, positive self-image and prosocial behavior. Empirical research indicates that adolescent mental health has been shown to be related to both educational attainment and occupational attainment (Slominski, Sameroff, Rosenblum \& Kasser, 2011). Similarly, according to Heckman and Kautz (2012), other benefits of strong SEL skills include predicted success in the labor market as well as life in general. Existing research by Jones, Greenberg \& Crowley (2015) highlight early SEL skills as being significantly related to wellness later in life. SEL has been associated with improved academic performance, physical health, and citizenship, while reducing the risk of maladjustment, failed relationships, interpersonal violence, substance abuse, and unhappiness; it is a skill set demanded by employers, and is considered essential for lifelong success (Elias et al., 1997; Zins, Weissberg, Wang \& Walberg, 2004). With the multitude of benefits, including both direct and indirect effects of well-developed SEL, it is thought to be as important to school success as cognitive and academic preparedness (Raver \& Zigler, 1997).

The benefits of well-developed SEL also include reduction of negative outcomes that are associated with limited development of appropriate skills (Elias \& Weissberg, 2000). Students that demonstrate poorer SEL can experience greater peer rejection, poorer relationships with teachers, risk of school failure, aggressive behaviors, temperamental difficulties, and poor self-control (Raver \& Knitzer, 2002; Jones et al., 2015). Specifically, students with low social and emotional functioning may go on to develop poor peer relationships, in which they engage in risky behaviors, such as underage drinking, unprotected sexual interactions and experimentation with illegal drugs 
(Catalano, Berglund, Ryan, Lonczak \& Hawkins, 2002). According to the National Center for Education Statistics (2002), of the reasons given for dropping out of school, many deal with social and emotional issues that can include teacher-student problems, not feeling safe, or feeling left out. Statistics from the NCES indicate the overall drop-out rate to be roughly $6.5 \%$ of all students, which is estimated to be between 700,000 and one million students in the United States (National Center for Education Statistics, 2015). The group also estimates that one-fifth of high school students are unsuccessful in graduating with their diploma within four years. In general, SEL is believed to make strong contributions to a child's overall wellbeing along with improving overall academic performance. Thus, SEL clearly has implications for both academic and social success. Moreover, when evidence-based SEL interventions have been implemented with youth, there have been positive impacts on improved social and emotional skills, attitudes, behavior, and academic performance (see meta-analysis by Durlak et al., 2011; Johnson \& Johnson, 2004; Payton et al., 2000; Elias, 2004). Parker et al. (2004) found higher SEL to be positively correlated to reported levels of student academic success at both the high school and college levels. It is clear that there are benefits of emphasizing and fostering SEL in students, particularly for academic outcomes. Academic achievement has been associated with many positive outcomes, such as better health and economic advantages (Johnson, Brett \& Deary, 2010) as well as success and career performance (Strenze, 2007). Not surprisingly then, there have been significant negative outcomes associated with low achievement and school withdrawal (Henry, Knight \& Thornberry, 2012; Waldfogel, Garfinkel, \& Kelly, 2005). Due to the host of positive outcomes, educators are focused on how to identify the best predictors of academic achievement in order to help foster protective factors in at-risk students (Salmela-Aro \& Tynkkynen, 2010).

\section{Ecological Systems Perspective}


As noted above, SEL is important for academic achievement. However, there must also be other factors contributing to the academic success of youth, and a major purpose of the current study is to understand whether other variables make significant contributions to achievement independent of SEL, or in combination with it. Indeed, some researchers believe that learning occurs not at an individual level, but rather based on collaboration between various individuals, including teachers, peers, and family members (Durlak et al., 2011). Similarly, the same holds true for SEL; there are individual child factors, family factors, and environmental factors to consider, that impact the development of these skills (Hemmeter, Ostrosky, \& Fox, 2006;).

Bronfenbrenner's bio-ecological perspective is one such way to view the varying impacts of multiple contexts on a child's overall development (Bronfenbrenner, 1979). He identified four interacting systems: the microsystem, mesosystem, exosystem, and macrosystem. At the core of this system of contextual influences is the individual and his/her unique characteristics. In this study, the focus is on variables at the individual/intrapersonal as well as microsystem levels. The microsystem consists of the child's most immediate environment, and is thought to serve as the child's reference point for his or her view of the world (Bronfenbrenner, 1979). While the family generally serves as children's first microsystem, this can expand to include friends, teachers, school, and the community as they mature. Microsystems help children develop physically, socially and psychologically, through face to face interactions with those around them.

It is important to consider a variety of risk and protective factors, because the microsystem is most proximal to children's daily lives and experiences, and likely the most impactful on their development. Risk factors are defined as variables that are associated with negative outcomes, as well as a greater probability of mental health issues (Coie et al., 1993). Examples of risk factors include growing up in poverty, single parent-homes, harsh parenting, peer rejection, and poor 
teacher-student relationships. Multiple risk factors can accumulate, which then leads to cumulative risk for children (Obradovic, Shaffer, \& Masten, 2012). This accumulation makes the need for information regarding protective factors so important. Protective factors, which are variables that may decrease dysfunction directly for those students at risk, are important to a student's SEL as well as academic achievement (Coie et al., 1993). They include both individual characteristics, such as disposition, as well as environmental attributes like school connectedness, positive relationships with parents or teachers (Furlong, Sharkey, Quirk \& Dowdy, 2011; Coie et al., 1993).

It is clear that social and emotional competence and academic success are interwoven (Zins \& Elias, 2006; Durlak et al., 1997; Johnson \& Johnson, 2004; Payton et al., 2000; Elias, 2004) and that children learn different skills based on the different environments they inhabit (Bronfenbrenner, 1979). These interactions work in shaping their overall development. As described above, ecological systems theory is important to take into account, as students are spending the majority of their time at home and in school, which suggests these environments can work together to strengthen the appropriate development of SEL. The experiences in the home, school and community settings can be reinforcing to youth's behaviors. Thus, using ecological systems theory, it is necessary to look at the variables that can ultimately impact development of SEL in adolescents. The variables that will be examined in this study include, at the intrapersonal level, students' self-perceptions of their social and emotional skills and their self-efficacy, and, at the microsystem level, students' levels of social support from peers, parents, and teachers, school climate, and parental involvement.

\section{Intrapersonal Factors}

Self-efficacy. In addition to SEL, as described above, self-efficacy will be included as a potential predictor of academic success, as it has been consistently found to be important correlates 
of both SEL and academic achievement. Self-efficacy can be defined as the explanation and prediction of one's emotions, actions, and thoughts (Bong \& Skaalvik, 2003). Self-efficacy is important as individuals gauge how successfully they can manage different experiences and situations, and is believed to be task-specific (Bandura, 1997). It is considered to be an essential component of youth development, and according to CASEL, falls under the self-awareness component of SEL.

With different types of functioning come different types of self-efficacy. According to Carroll et al. (2009), these types include academic self-efficacy, emotional self-efficacy, and social self-efficacy. All three types have shown to have positive influences on student academic achievement (Carroll et al., 2009; Qualter, Gardener, Pope, Hutchinson, \& Whiteley, 2012; Affuso, Bacchini, Miranda, 2016). Overall, previous research has demonstrated that self-efficacy is a predictor of an individual's total educational achievement (Lent, Larkin \& Brown, 1986; Schunk, Pintrick \& Meece, 2010; Chemers, Hu \& Garcia, 2001; Bandura, 1997).

\section{Microsystem Predictors}

An important factor in promoting increased academic achievement is having students cultivate meaningful relationships with peers, teachers and parents (Martin \& Dowson, 2009). Social support is defined by Malecki \& Demaray (2002) as an individual's perceptions of supportive characteristics from individuals in his or her social network that may improve functioning and may act as a buffer from negative outcomes. This type of support is thought to be based on the perception of how much social support one has made available to them if so needed. The social network can include parents, teachers, friends, close friends, and the school (Malecki \& Demaray, 2002). Social support can serve as a protective factor when individuals are able to rely on others; however, when individuals lack perceived social support, they may experience more 
negative and adverse outcomes. In addition, the various sources of social support for children and adolescents is thought to be dependent on age. For example, children are more likely to turn to their parents when they are younger, however, during adolescence, they may grow to look to peers and significant others as that source of support (Furman \& Buhrmester, 1992).

There are different sources of social support, including parent support, teacher support, and peer support. Research on perceived social support shows that it is positively correlated with academic achievement in young adults (Rosenfeld, Richman \& Bowen, 2000). Research suggests that students with perceived higher levels of support from teachers, parents and peers earned better grades compared to those students lacking perceived social support (Rosenfeld et al., 2000; Domagała-Zyśk, 2006). Thus, it lends support to the idea that increased levels of social support is a predictor of higher grades and overall academic achievement.

Peer support. To begin with, peer support increases during the transition from childhood to adolescence, where youth begin to look to peers and friends to influence their behaviors. These behaviors can translate to influence academic behaviors in the school setting, thus impacting more school-related outcomes. Peer support can take on many different meanings; this could be modeled by peers helping with homework, offering words of encouragement, or working together towards a common academic goal. In any case, peer groups are thought to greatly impact how students view achievement (Nicols \& White, 2001). Peers may be even more influential when they are considered good friends (Goldsmith, 2004). Evidence suggests peer support positively impacts academic achievement. For example, Wentzel, McNamara Barry, and Caldwell (2004) found that adolescents with academically high performing friends not only showed improvement in their own academic achievement, but also increased involvement in school. In addition, students' own academic competencies have been shown to be associated with their friends' academic competence 
and support (Bissell-Harvan \& Loken, 2009). However, just as peer support can be considered a protective factor for at-risk youth, it can also operate as a risk factor. Some students may feel pressure to conform to negative peer pressure, or other norms that detract from increased academic achievement (Wentzel \& Caldwell, 1997; Goldsmith, 2004).

Parent support. Parents provide great influence on children's overall development. Parent support also is found to be an important factor in a student's academic success. Research has indicated that parents play a necessary role in fostering high achievement in their children throughout childhood and adolescence (Bouchey \& Harter, 2005). Parents lend perhaps the greatest level of support during infancy and into early and middle childhood. However, despite increased autonomy during adolescence, parents are still found to be involved in teens' decision making processes regarding major life choices (Kerpelman, Eryigit \& Stephens, 2008). In addition, this support continues through young adulthood. Parental support has shown to positively impact college students' academics (Cutrona, Cole, Colangelo, Assouline, \& Russel, 1994). Some find parental support to be the best predictor for overall psychological functioning, when compared to teacher support and peer support (Stewart \& Suldo, 2011).

Teacher support. Nonetheless, the impact teachers can have on students' academic performance has also been well-documented. The relationship between a student and teacher is deemed to be a significant predictor of a student's academic and social-emotional competence (Tennant et al., 2015). Teacher support is thought to encompass characteristics such as warmth and acceptance, as well as providing knowledge and feedback to students (Tennant et al., 2015). This type of support is associated with a plethora of positive outcomes for students within the academic, social, and behavioral domains (Bryan et al., 2012). For example, Malecki and Elliot (1999) found there to be a significant relationship between teacher support and middle and high 
schoolers' grade point average (GPA). In addition, Tennant and colleagues (2015) found that teacher social support, specifically emotional support, was significantly and positively related to students' GPA suggesting that greater teacher emotional support is related to higher academic achievement. In terms of SEL, empirical evidence suggests emotional and instrumental teacher support to be significantly related to middle school students' well-being (Suldo et al., 2009). In addition, research has linked teacher emotional support to positive social-emotional competence (Tennant et al., 2015). Other findings suggest increased perceived teacher support is related to better social-emotional adjustment (Murray \& Greenberg, 2000).

Parental involvement. Further, parental involvement is considered to be important in helping to facilitate a student's overall positive development, academic success, and motivation to learn (Epstein \& Sanders, 2002; Hill \& Taylor, 2004; Jeynes, 2012; Seginer, 2006). Parental involvement is defined as the interactions parents have with the school, as well as their interactions with children in order to benefit their children's academic success (Hill et al., 2004). Research indicates that when there are high parental aspirations for children in high school, there is a positive outcome with students' academic performance (Catsambis, 2001). Parental involvement has also indicated success not just academically, but with emotional functioning as well at the high school level (Wang \& Sheikh-Khalil, 2014). Furthermore, parent involvement was found to be associated with a higher percentage of homework completed as well as the time students spend working on homework (Epstein \& Sanders, 2002).

School climate. Lastly, school climate is important to consider when looking at both academic and emotional competencies. While there is no universal definition of school climate, it can be thought of as the overarching beliefs, values and attitudes of students, teachers, parents, and community members (Cohen, 2009). It essentially focuses on the overall quality of school life. 
School climate emphasizes the interactions between all members within the community, instead of relying on individual experiences. As a result, school climate greatly impacts experiences on every level, for all individuals, including students, teachers, parents, etc.

Overall, research suggests a link between positive school climate and greater academic achievement (Stewart, 2008; Wang \& Degol, 2016; Thapa, Guffey, \& Higgins-D’Alessandro, 2013). In addition, Bear, Gaskins, Blank, and Chen (2014) found positive school climate perceptions to be positively correlated with mean standardized tests scores. Schools should be safe, encouraging and inclusive environments that look to foster the whole child and his or her full potential. However, reports suggest not all students feel safe or included in their school settings (Grover, Boberiene, \& Limber, 2015; Robers, Kemp, \& Truman, 2013). Schools that are perceived as unhealthy seem to have environments in which staff appear unmotivated and academics and student achievement are not highly valued (Hoy \& Tarter, 1997). As a result, school climate can act as a potential risk-factor for students or a protective factor.

\section{Limitations of Prior Research and Purpose of Proposed Study}

As there continues to be growing evidence highlighting the benefits to academic success of social and emotional competencies, there are also limitations to the current research. To begin with, the term SEL is viewed as an umbrella term, which makes specific skills difficult to operationalize, and the idea somewhat ambiguous (Hoffman, 2008). For example, it has been referred to as emotional intelligence or SEL in the literature, among other names. In addition, there are concerns with the cultural differences in demonstrating and communicating emotions (Hoffman, 2008). For example, there are concerns the social and emotional programs being utilized are heavily Westernized ways of expressing and dealing with emotions, which may not generalize to all cultures. 
In addition, while CASEL's definition of SEL is described as well-known in the field (Osher et al., 2016), there is no one model that is believed to capture all of the specific elements of social and emotional learning (Payton et al., 2000). As a result, the idea of SEL draws from many different theories, including Social Cognitive Theory, Social Information Processing and Problem Behavior Theory, among others. This makes it difficult to understand the model in which competencies are developed, and which of the components are responsible for the most beneficial outcomes. Osher et al. (2016) also highlight the lack of alignment among the different frameworks of SEL. They stress the importance of creating clear and common language to bridge the differing conceptualizations.

It is also necessary to note there has been some scrutiny for the lack of experimental studies that specifically look at the relationship between SEL and increased academic performance (Durlak et al., 2011), particularly when including other carefully sampled variables from a child's broad ecology. Based on the meta-analysis conducted by Durlak et al. (2011), only $16 \%$ of intervention programs collected academic performance information post treatment. These are things to consider when moving forward with the current study. It is also necessary to think about how social and emotional learning can interact with the rest of a child's ecology. A child's competence in SEL is likely impacted by multiple factors within their ecological context. Students who demonstrate more social and emotional learning may have stronger self-efficacy and more positive relationships with others in their lives.

As more and more children are arriving at school without knowledge of SEL, it is important that teachers and parents recognize how to model and help children develop these necessary competencies, specifically to encourage school success. While there is valuable research available on social and emotional development for students, there is a limitation when examining SEL from 
the ecological perspective, specifically looking at variables within the home, school, and community settings, and those individuals involved in a child's life. The purpose of the study will be to comprehensively examine academic achievement and SEL from an ecological perspective.

\section{Research Questions}

Based on the above information, the research questions to be addressed include the following:

1. How strongly correlated are SEL and achievement?

2. Of the two intrapersonal variables (social emotional learning, self-efficacy) which is most predictive of academic achievement?

3. What microsystem (peer support, teacher support, parent support, parental involvement) variables are most predictive of academic achievement?

4. In a combined model, do the microsystem variables and self-efficacy significantly predict achievement above and beyond SEL?

\section{Significance of the Study}

The results of this study are expected to contribute a more thorough understanding of the predictors of academic achievement among high school students, with variables carefully selected using an ecological approach. It is expected that with the selection of variables from this ecological perspective, it will help to more thoroughly explain the variance in academic achievement in high school adolescents. With a movement towards educating the whole child, it is necessary to determine the influence that these variables have on achievement. While research has indicated all variables have some positive impact on achievement, they have not compared the variables to one another in relation to predictors of achievement. In addition, the goal of this research is to specifically identify the importance of SEL on academic achievement and to examine whether other variables matter and how much. 
Through this study a specific model of looking at the ideas of how ecological factors contribute to academic achievement is proposed. Payton et al. (2000) suggested in an earlier CASEL description, that awareness of self and others, and positive attitudes and values were the foundation in developing the other competencies of responsible decision making and social interaction skills. If this is believed to be true, intrapersonal factors such as self-efficacy will be necessary in displaying increased social-emotional learning. These efficacious beliefs are hypothesized to then in turn impact the social relationships students have with teachers, peers and parents. The way adolescents view their interactions with teachers, parents and peers will likely influence their perception of school climate. All of these ecological factors are believed to have some positive impact on academic achievement.

With the trend of educators looking to build and incorporate SEL skills into state curriculum standards, it is necessary to understand the relationship SEL plays on adolescent achievement. SEL is hypothesized to be the biggest predictor of academic achievement compared to other variables, including self-efficacy and various microsystem supports. It is believed because SEL incorporates a host of skills that are paramount to school success, that it will best explain the variance in achievement. The results of this study will provide an increased understanding of the predictors of academic achievement in adolescents. It may aid in the knowledge needed to implement specific, targeted, evidenced-based interventions to increase high school students' academic achievement. 


\section{CHAPTER 2 REVIEW OF LITERATURE}

Social and emotional learning (SEL) is becoming a growing area of interest among educators, psychologists, parents and those in the medical field. This may be due to the increasing number of children and adolescents displaying characteristics of mental health disorders (Tolan \& Dodge, 2005). In addition, there is concern that mental health is often overlooked, and as a result, children and adolescents may be underserved. Some estimate as many as $80 \%$ of children and adolescent symptoms of mental health illness may go untreated (Breslau, Lane, Sampson \& Kessler, 2010). This could partly be due to a lack of adequate mental health services available for the increasing need of children and adolescents in the United States (Burns et al., 1995). The youth who have diagnosable disorders are not seeking the necessary support or services needed to provide them with strategies and coping skills. Unfortunately, estimates are even worse for

minority children and those within the low socioeconomic range. According to Ringel and Sturm (2001), only $13 \%$ of minority group children accessed children's mental health services in a way that met their needs, compared to $31 \%$ of nonminority children. Service barriers can include lack of available professionals in low-income neighborhoods, limited transportation access to community mental health centers, cultural differences, practitioners lacking cultural competency, and inadequate funds for treatment (Tolan \& Dodge, 2005). As a result, there is great need to identify ways to help support students at risk of these disorders.

The negative impacts of mental disorders can be seen at the child and adolescent level. For example, these groups are at a much greater risk for suffering long-term negative effects, such as increased drop-out rates and long-term impairments (Breslau et al., 2010). Greenberg, Domitrovich, and Bumbarger (2001) found mental health difficulties to be related to lower academic achievement. In addition, mental health issues have been shown to be interrelated to 
many other negative outcomes, including greater stress within a familial unit, increased risk of school failure, and decreased social competencies that can persist into adulthood (Fisher et al, 1997; Greenberg et al., 2001; Mrazek, Biglan \& Hawkins, 2007). This is a societal concern because the majority of adults with disorders report their symptoms began when they were younger, during childhood or adolescence (Kessler et al., 2005).

Focusing on providing mental health psychoeducation to children, families and educators, as well as solutions, such as evidence-based interventions, may lead to better outcomes for all involved. Greenberg et al. (2003) suggest that promoting mental health can lead to better functioning across multiple areas of child development, due to an assumed reciprocal relationship. The idea of reciprocity is important when thinking about mental health and different areas of development; if something is improving for one area, it may lead to growth within another area, leading to overall healthier development for children.

It is not just mental health of children that should be a concern. In terms of educational performance, there is a large percentage of students who are performing below the proficient benchmark in reading, writing and mathematics (National Center for Education Statistics). Only $42 \%$ of fourth graders performed at the proficient level for mathematics in 2013. It is even lower for students in middle school, with roughly $35 \%$ of eighth graders meeting the proficient benchmark for mathematics the same year. The reading scores were even lower for elementary students - with $35 \%$ of fourth graders performing in the proficient range; middle schoolers do not fare much better, with only $36 \%$ of eighth graders performing in the proficient range for reading. There is even greater disparity between Caucasian and African American students' performances, which has been identified as the achievement gap. Krueger, Whitmore, Chubb \& Lovelace (2002) found that on average, African American students perform at about the same level as the lowest 
performing Caucasian student. According to the National Assessment of Education Progress (NAEP), 80\% of fourth-grade students from low-income backgrounds score below grade level for reading. This means to suggest that despite the country's best efforts, students are lagging not only in mental health competencies, but also in academic competencies.

The national educational difficulties are evident when comparing the progress of the US students with those from around the world. Based on data from the Program for International Student Assessment (PISA) for 2012, students from the United States are behind in math and science compared to those students from the international community. The United States placed $27^{\text {th }}$ out of a total of 34 countries in the area of math performance, and $20^{\text {th }}$ out of 34 countries in science performance. The reading differences are lesser, although the United States ranks $17^{\text {th }}$ in this subject. There have been no significant changes in performances within these areas over time. Due to the limited student proficiency and general progress within multiple academic areas in the United States, there continue to be concerns over the way instruction is being implemented within the country's schools, and students' overall academic performance.

In the $21^{\text {st }}$ century, educators recognize the need for students to develop competencies that impact the development and well-being of the whole child. Having instruction solely in the areas of math, literacy and science is no longer considered enough for educators to focus on. Rather there needs to be incorporation of academics, as well as the instruction for students to demonstrate non-cognitive and emotionally intelligent skills There are other factors that lead to increased educational performance, as well as students producing productive members of society. These factors, focusing on the social and emotional competencies of students, are thought of as influencing and impacting one another.

\section{Impact of Social and Emotional Learning}


How and what one learns is affected by relationships as well as emotional process (Elias et al., 1997). As a result, SEL competencies play a pivotal role in not only academic development, but the overall development of children (Zins et al., 2004). According to Zins et al. (2004) SEL can positively impact attitudes, behavior and performance within the school environment. Similarly, a meta-analysis by Durlak et al. (2011) found many benefits of implementing SEL programs within the school setting. Social and emotional competencies have been found to be a significant predictor of academic success (Parker et al., 2004).

It is necessary for schools to recognize the benefits of promoting this specific skill set for a child's overall development. Emphasis on recognizing the benefits of incorporating a focus on SEL within the school setting is evident (Protheroe, 2012). State departments of education throughout the United States have taken notice. For example, the state of Illinois has already adopted and implemented social and emotional learning goals and benchmarks (Dusenbury, Zadrazil, Mart \& Weissberg, 2011). Other states are moving towards merging SEL content with another set of learning standards, such as math or language arts (Dusenbury et al., 2011). In addition, Foster et al. (2005) indicate that a total of 59\% of all schools in the US have programming to promote and support the development of social emotional skills.

SEL competencies are necessary for children's academic and personal success. The need for implementation and incorporation of these skills is great. In a national sample of nearly 150,000 middle school and high school students, only $29 \%$ - $45 \%$ of students reported having social and emotional skills (Benson, 2006). Blum, Libbey, Bishop \& Bishop (2004) found that those students lacking in social-emotional competencies can become less connected to school, which not only negatively impacts academic achievement, but also has behavior and health consequences. Failure to develop SEL skills can lead to issues at all developmental levels (Guerra \& Bradshaw, 2008). 
According to Adelman \& Taylor (2006) state schools that focus their efforts of trying to increase academic success simply through academic instruction coupled with school management are thought to be unsuccessful. The argument is these types of schools are missing the key component of SEL. This type of learning is integral to help children succeed in the school setting (Zins et al., 2004).

As mentioned previously, the five components identified by the Collaborative for Academic, Social and Emotional Learning (CASEL) include self-awareness, social awareness, responsible decision making, self-management and relationship management (CASEL, 2015). These are thought to encompass a set of skills that help to create competent individuals who not only display improved school attitudes, school behavior, and school performance, but ultimately individuals that can be well-functioning adults within society (Zins et al., 2004). Overall, students displaying well developed SEL skills are believed to demonstrate success within other areas, such as academic achievement, problem solving, and conflict resolution.

The first component, self-awareness is defined as "the ability to accurately recognize one's own emotions, thoughts, and values and how they influence behavior" (CASEL, 2015). Particular skills for this component include identifying and recognizing emotions, self-efficacy, spirituality, and recognizing strengths, needs and values (Zins et al., 2004). These skills are more intrapersonally based, as they lie within the individual. Utilizing a "growth mindset" may be particular helpful when looking to improve self-awareness skills. Examples of students displaying self-awareness, in an educational context, could include a student recognizing and communicating to his teacher that he is frustrated, or another student identifying spelling is an area of weakness for her and coming up with strategies to help her remember letter patterns.

Next, self-management is defined as “the ability to successfully regulate one's emotions, 
thoughts, and behaviors in different situations; effectively managing stress, controlling impulses, and motivating oneself' (CASEL, 2015). According to Zins et al. (2004) skills can include impulse control and stress management, self-motivation and discipline, as well as goal setting and organizational skills. Students who display appropriate levels of self-management are believed to be able to set and work toward personal and academic goals. Having students track or monitor grades or missing assignments weekly may be a way in which to build upon self-management skills.

Social awareness is the third component identified by CASEL. The group defines this component as "the ability to take the perspective and empathize with others, including those from diverse backgrounds and cultures" (CASEL, 2015). This component also places emphasis on the ability to understand social and ethical norms for behaviors, while recognizing family, school, and community supports. For students, the ability to "put themselves in another's shoes" is an important skill to possess under this component. It highlights the differences individuals bring to the table, and celebrates diversity, through respect of these differences.

In addition, relationship skills or management is identified as another component of SEL. Relationships skills is defined as "the ability to establish and maintain healthy and rewarding relationships with diverse individuals and groups" (CASEL, 2015). According to Zins et al. (2004) skills in this area include negotiation, refusal, and conflict management; help seeking and providing; communication, social engagement and building relationships. It is important for students in the school setting to be connected to those around them, through positive interactions with peers and teachers. If conflict does occur, being able to problem solve and look for creative solutions demonstrates development of these skills. One specific SEL program that led to increased academic achievement, by focusing on relationship management of students, was The Three C's 
of promoting social and emotional learning (Johnson \& Johnson, 2004). This program focuses on three c's including: cooperative community, constructive conflict resolution and civic values. Johnson and Johnson (2002) suggest cooperation tends to promote higher achievement among students. This may occur as individuals work to promote one another's success, instead of being more competitive and individualistically focused. They found that students working cooperatively tended to spend more time on tasks and were more engaged in the lesson compared to when students worked on their own. Creating opportunities for students to work together in the classroom may promote increased cooperation amongst students. In addition, they identified conflict resolution training as an integral piece of SEL. When students were able to successfully engage in conflict resolution training, academic achievement increased, with an effect size of .88, as did long-term retention of academic material, with a .70 effect size (Johnson \& Johnson, 1989).

Lastly, the component of responsible decision making is thought to be "the ability to make constructive choices about personal behavior and social interactions based on ethical standards, safety concerns, and social norms" (CASEL, 2015). Important skills that fall under this component can include problem identification and situation analysis, engaging in problem solving techniques, and reflecting and evaluating, all while keeping in mind ethical responsibility in terms of the wellbeing of oneself and others. Another SEL intervention program that resulted in a trend of increased academic performance was that of the Social Decision Making (SDM) and Social Problem Solving (SPM) program. The program focused explicitly on teaching a basic set of problem solving and decision making skills within the school setting. Implementation of this program led to gains in language arts grades among fifth graders. In addition to improvements in language arts performance, this program also positively impacted social studies grades (Payton et al., 2000).

Evidence-based SEL programs can influence academic success for students. According to 
Zins et al. (2004) these programs can provide opportunities and rewards for better, more positive behavior. At the same time, these programs can foster safe, caring learning environments for students. These improved environments can then lead to strengthening of the SEL competencies identified by CASEL (2005). As a result, students may engage in less risky behavior and demonstrate more positive and adaptive development. These positive effects can influence greater school attachment, commitment and encouragement in students. All of these positive outcomes can lead to better academic performance and achievement within the school setting.

Academic achievement has been associated with many positive outcomes. This includes better health and economic advantages, as individual have access to more opportunities (Johnson et al., 2010), and career success (Strenze, 2007). In addition, students who reported higher levels of global life satisfaction reported significantly higher academic functioning than youth who reported lower life satisfaction (Gilman \& Huebner, 2006).

However, just as high academic achievement can act as a protective factor for some students, it can also be a risk-factor when performance is low. Students who drop out or fail to graduate due to low achievement have higher levels of unemployment as well as lower earnings, and are more likely to be dependent on public assistance (Henry et al., 2012; Waldfogel et al., 2005). In addition, risk of delinquent behaviors can increase as well, including increased substance use along with a significant increase in the likelihood of involvement in crime and incarceration (Henry et al., 2012; Jimerson, Egeland, Sroufe, \& Carlson, 2000; Moretti, 2005). Overall, students who display academic underachievement display significantly poorer health compared to students who do well academically (Henry et al., 2012). Because of the host of positive outcomes for academic success, educators are focused on how to identify the best predictors of academic achievement in order to help students at-risk of failure and the long lasting negative consequences 
associated with underachievement (Samela-Aro \& Tynkkynen, 2010). In order to do so, it is necessary to examine the different contexts that impact student development.

\section{Ecological Model}

Bronfenbrenner's ecological systems theory examines the development of an individual based on his or her interactions within his or her environments. Development, which he describes as lasting change, is a result of how an individual perceives and handles his or her environment (Bronfenbrenner, 1979). This is not to say that only an immediate setting will impact an individual, in this case, a student. Rather, there are interconnections depending on all contexts within the environments that a student encounters. According to Bronfenbrenner, "A child's ability to learn to read in the primary grades may depend no less on how he is taught than on the existence and nature of ties between the school and home" (Bronfenbrenner, 1979, p. 3). This quotation highlights the idea that learning does not only occur within the school setting; it goes well beyond the delivery of the content.

An important consideration in his theory, is acknowledged in the role of the dyad, or the two-person system. Bronfenbrenner (1979) suggests if one member of the dyad undergoes lasting change, then it is likely the other member changes as well. This is especially important to understand in the context of a student, who has dyadic relationships with parents, teachers, peers and administrators within the school setting. Dyads are based on the idea of reciprocity, or recognizing that there is influence between an individual as well as the other person he or she is interacting with. For example, a parent's response to a child's behavior will likely influence that behavior in the future. A teacher's response to a student asking a question will likely influence that child's behavior in the future. The same goes for the individual's influence on the other individual he or she interacts with. 
A main idea in this development theory is to understand the direct and indirect environments that influence a child's development - including the home, school community, and culture. There are unique environmental variables that impact development within different systems. There are a total of four different systems within Bronfenbrenner's ecological development theory: microsystems, mesosystems, exosystems, and macrosystems (Bronfenbrenner, 1979). He originally presented his theory as a set of contexts nested within each other; an individual is located within the microsystem level, which is inside the mesosystem level, which is inside the exosystem level, which all lies within the macrosystem. Two decades after Bronfenbrenner's original model, the idea of proximal processes was introduced, consisting of reciprocal interactions between the individual and the different contexts of the systems within the ecological systems theory.

A microsystem is thought to be how an individual interacts with his or her direct settings. This context is important, as it accounts for face-to-face or direct interactions between an individual and environment (Bronfenbrenner, 1979). Schools, homes, neighborhoods, and churches can all be identified as microsystems. These direct interactions are influenced by factors such as roles, activities and relationships individuals experience within a microsystem. Bronfenbrenner (1979) identified these factors as building blocks of the microsystem. He defines roles as expectations and behaviors that are based on one's position. An individual's experiences are based on the different roles of others he or she interacts with, as well as his or her own perceived role. Activities are valued within the microsystem. For example, activities such as participation in band, sports or clubs in a school setting may impact the role an individual has within the microsystem. An example framed in an educational way could include a student having a teacher who also serves as his or her athletic coach. 
A mesosystem, the next level of the ecological systems theory, is conceptualized as the relationships or interactions between different microsystems (Bronfenbrenner, 1979). One can think of a mesosystem as two or more settings interacting together. An example, framed in an educational context, could include parents interacting with their children's school through exchanges such as curriculum night or parent-teacher conferences. Other examples could include when school administrators contact parents due to behavior concerns, when school personnel hold special education meetings with families, or discuss school suspensions with parents or guardians.

Next, the third system in Bronfenbrenner's ecological systems theory focuses on the exosystem. While these are systems that influence an individual, the individual is not a direct participant. An example framed in an educational context could include a school district consolidating schools in an effort to save money (Neal \& Neal, 2013). This change within the system could ultimately impact the number of students per classroom as well as students per school. While the student is not directly participating in the system, the decisions made in the exosystem has the potential to influence the student's microsystems and mesosystems. Another example could include a sibling of an individual attending a class at school with a specific teacher. While the individual is not interacting with both directly, the student may have that teacher at some point in his or her educational career, which could influence their relationship.

The last and largest system in Bronfenbrenner's theory is the macrosystem. This system emphasizes broad cultural influences, beliefs or ideologies that impact an individual (Bronfenbrenner, 1979). It could be argued the passing of the No Child Left Behind Bill may be considered something happening at a macrosystem level. This particular ideology focuses efforts on improving academic performance through standardized testing and can indirectly impact student development. Today, there is more pressure on students to perform well on these "high- 
stakes" tests, as they serve as a way to evaluate the overall effectiveness of school districts as well as teachers working within them. This kind of law impacts how education is viewed on a national level.

Overall, the focus of the current study will highlight the roles of the intrapersonal variables found within an individual as well as the impact of different microsystem interactions specific to an adolescent student. Taken together, Bronfenbrenner's ecological systems theory suggests that environments and interactions ultimately shape a student's success. Strayhorn (2010) finds that a plethora of microsystem variables, such as parental involvement, achievement in school, and peer relationships, have a tremendous impact on the development of a student. A collective of interactions and experiences come together to positively or negatively shape and influence development.

While looking at the ecological systems theory, it is important to understand how risks and protective factors can impact students. Risks are defined as variables associated with greater potential for adverse problems (Coie et al., 1993). It is important to note that rarely are singular risks cause for maladjustment. Cumulative risk is identified as the degree of exposure to high levels of risk across multiple sources; at times this accumulation may have an additive effect, meaning the more risks a student is exposed to, the more likely they are to be negatively impacted. Taking into account the different contexts within Bronfenbrenner's theory, it is likely that children exposed to multiple stressful environments are more vulnerable compared to other children who are not exposed or predisposed to the same number of stressors. Examples of risk factors in the school microsystem can include number of days absent, inexperienced teachers, and transiency between schools. Risk factors that could be attributed to neighborhoods, which would also be occurring at the microsystem or mesosytem level, can include percentage of the population living 
below the poverty line as well as the number of violent crimes in the area. Whipple, Evans, Barry \& Maxwell (2010) found that cumulative risk exposure can predict school-wide achievement. As a result, it is important to recognize risk factors for students within the school setting and look to increase students' resiliency.

Despite facing multiple risk factors, children are still able to demonstrate remarkable resiliency. This resiliency is likely influenced by protective factors, or processes, that are thought of as individual or environmental safeguards that enhance children's competence and adaptive skills, as well as reduce the the impact of stressors in their lives (Steinberg, 1991). The ecological component emphasizes both characteristics that are within the individual, and within the individual's environments (Bogenschneider, 1996). Examples of protective factors can include high self-efficacy, a positive relationship with a teacher, school connectedness, peer acceptance, high parental education, etc.

All factors that will be examined in the current study have the potential to be a risk or protective factor, depending on an adolescent's perspective and experience. Human development can be negatively influenced when exposed to multiple risks, just as it can be positively influenced by multiple protective factors. A simplified way to view the impact of risk and protective factors, is to say that the more risks a student faces, the greater the danger, whereas the more protective factors, the greater the likelihood for appropriate and positive development (Bogenschneider, 1996). As SEL is one intrapersonal factor that is shown to positively impact academic achievement, it is necessary to examine other factors as well, in keeping with the ecological systems theory. These factors, which have all been shown to positively impact achievement as well, include self-efficacy, peer support, parent support, teacher support, parental involvement and school climate. They all have the potential to act as protective factors. 


\section{Intrapersonal Factor}

Self-efficacy. Self-efficacy, which is thought to be beliefs regarding an ability to perform specific tasks in a successful manner (Bandura, 1995), is an important factor to consider when looking at high school students' academic performance. It is a construct that is conceptualized as existing within the individual, or intrapersonally. Self-efficacy is task-specific, with the idea that no individual can do all things well - each has strengths and weaknesses. Bandura (1995) explains what an individual believes he or she is capable of influences performance and outcomes. He identified four sources of information that allow individuals to determine capability: vicarious experience, verbal persuasion, emotional and physiological states, and enactive learning (Bandura, 1997). Vicarious experience explains people establishing their own beliefs on the basis of others', who are similar to them, performances on tasks. Verbal persuasion is communication and feedback from significant others that can influence one's judgment. Physiological reactions include heartbeats, pain, and mood changes that send signals to individuals. Lastly, enactive learning is based on previous experiences with specific tasks (Bandura, 1997; Bong \& Skaalvik, 2003).

Bandura and colleagues (1996) suggest those students that feel more efficacious are more likely to persist in their current academics. As a result, self-efficacy is a strong predictor of academic achievement (Schunk et al., 2010; Galyon, Blondin, Yaw, Nalls, \& Williams, 2012; Zimmerman, 2000). Adolescent students who feel more efficacious are more likely than their less efficacious feeling peers to form logical and thoughtful plans, challenge their own abilities, and set concrete goals for themselves. These are all positive attributes that can help students be successful in the school setting. Carroll et al. (2009) discussed three different types of self-efficacy: academic self-efficacy, social self-efficacy and emotional self-efficacy; all of which have demonstrated to be positively linked to increased academic achievement. 
Academic self-efficacy is a specific form of self-efficacy. This type of efficacy is thought to be related to the way in which students feel regarding their ability to learn new information and demonstrate mastery of information through educational performances (Zimmerman, 1995). Specific to academic self-efficacy, many researchers have found a positive correlation between academic achievement and academic self-efficacy (Bandura, Barbaranelli, Caprara \& Pastorelli, 1996; Greene, Miller, Crowson, Duke \& Akey, 2004). In addition, Carroll and colleagues (2009) extrapolated similar results. Based on significant findings, academic self-efficacy is considered a specific predictor of academic performance (Brown et al., 2008).

Social self-efficacy is believed to encompass an individual's willingness to engage or initiate behavior in social situations (Wheeler \& Lad, 1982). This type of self-efficacy helps children and adolescents form and maintain appropriate relationships with peers, demonstrate prosocial behaviors, and receive positive peer praise - all of which have been found to be correlated with academic achievement (Patrick, Hicks \& Ryan, 1997). In addition, children who had stronger social self-efficacy beliefs were not only enabled to form and maintain appropriate peer relationships, but also to demonstrate academic success (Bandura et al., 1996).

Emotional self-efficacy is thought to encompass an individual's capabilities of emotional functioning (Dacre Pool \& Qualter, 2012). It can be the way individuals think they can be successful in their perceptions, uses, understanding and managing of emotional information (Qualter et al., 2015). Emotional self-efficacy is believed to help individuals deal with and manage negative emotional experiences so they do not become overwhelmed in the face of them. Some believe it to be an important construct of trait Emotional Intelligence (Qualter et al., 2012), and thus argue it is important for academic success and performance. Emotional self-efficacy is also 
found to help with future success, as Dacre Pool \& Qualter (2012) found it to be significantly related to higher employability.

\section{Microsystem Predictors}

According to attachment theory, a level of social connectedness is necessary for children. It serves as model in teaching children to respect social institutions as well as to understand the social standards within these institutions (Baker, 1999). These social connections impact development. While there have been numerous definitions of social support, Cobb (1976) identified three necessary components of support to include feeling loved, feeling valued and belonging to a social network. Social supports, viewed through an ecological lens, are considered to be proximal influences that ultimately impact intrapersonal variables within individuals (Anderman, 1999). Some of the most common social connections that occur throughout childhood and adolescence include those connections with parents, peers and teachers, as children spend the most time in the home and school settings.

Perceived social support may act as a protective factor to promote positive development and behavior in individuals. In an adolescent's world, teachers, parents, and peers all play a vital role in supporting his or her development. Rosenfeld et al. (2000) suggest social support helps promote student success within a school setting. Student development within a school setting is believed to be impacted by the quality of support from others they interact with regularly (Chen, 2005). Student's educational experiences are enriched by having supportive individuals within their social contexts. Support can influence many different positive outcomes in education, including student motivation, school adjustment, sense of school coherence, the number of students dropping out of school, attendance and motivation (Rosenfeld et al., 2000).

Three sources of social support will be further explored when looking to promote academic 
achievement in adolescents: peer support, parent support and teacher support. Academic behaviors and attitudes are influenced by those individuals who interact with students on a regular basis, including teachers, parents and peers (Legault, Green-Demers, Pelletier, 2006). Rosenfeld et al. (2000) suggest when a student describes the combination of these three sources of support as highly supportive, students have better school outcomes. The group reporting higher levels of support within the sample had better attendance, better grades, and higher school satisfaction (Rosenfeld et al., 2000). However, students who reported receiving low support were shown to have the poorest school outcomes (Rosenfeld et al., 2000). Further lending evidence to the importance of social support, Martin \& Dowson (2009) found that social relationships positively influence academic achievement.

Peer support. Peer relationships play an integral part in a student's sense of belonging. Friendships and peer acceptance are important childhood experiences throughout schooling, beginning in pre-school or kindergarten for students. However, adolescence is the time of development in which peer group membership is critical (Rubin, Bukowski, \& Parker, 2006). During this time, peers are credited with highly influencing a student's day to day behavior. Peers can impact how engaged students are during class, how much time they spend on extracurricular school activities, or impact the transition between middle school to high school. Isakson \& Jarvis (1999) found that students who reported peer support during the transition from eighth grade to high school felt the transition was smoother compared to those who did not perceive peer support.

Peer support is a variable that has shown to influence academic achievement. According to Wentzel et al. (2004) the type of friends a student has in school matters. Specifically, adolescents with high performing friends showed improvement in their academic achievement, along with increased involvement in school activities. This exemplifies peer influence on students' 
educational behaviors. For example, if a student sees his friend working in class, that may encourage him to stay on task and behavior similarly. Bissell-Harvan \& Loken (2009) found students own academic competencies have been shown to be associated with academic competencies and support of their friends. Peer support can serve to act as a protective factor, or it can also serve to act as a risk-factor for some adolescents. According to Wentzel and Caldwell (1997), some students may give in to negative influences in order to conform to peer pressure. This can result in students engaging in risky behaviors that may lead to decreased school performance or engagement. In addition, those students who are socially rejected by peers are more likely to become disinterested in academics (Sage \& Kindermann, 1999). Peer support is an important variable when looking at predictors of academic achievement in adolescents.

Parent support. In addition, parents greatly influence children's development and behaviors throughout childhood and adolescence. Young children are dependent on their parents and as a result, parents are able to assert more influence in the home setting, through parenting practices and continuous interactions. While parental support is thought to be more important during infancy, early childhood, and middle childhood, it appears to remain critical in adolescence as well. Kerpelman et al. (2008) found parents continue to be involved in adolescents' decision making about major life choices. Maintaining relationships with parents during adolescence may serve as a protective factor. According to Maccoby \& Martin (1983), adolescents that maintain close relationships with their parents display greater independence and self-confidence compared to those adolescents who do not have as strong of relationships.

Research examining the relationship between parent support and academic achievement in students demonstrates parents continue to play an important role, despite adolescents looking for more autonomy (Kerpelman et al., 2008). Previous studies highlight the positive influence parental 
support can have on children academically (Bouchey \& Harter, 2005; Stewart \& Suldo, 2011; Gordon \& Cui, 2012). In addition, Murray (2009) uncovered a significant relationship between supportive relationships between parent and child and a child's academic performance. Parental support in education can be shown in a variety of ways, including the way in which parents value education, and openly communicate about academic expectations with their children (Jodl, Michael, Malanchuk, Ecceles, \& Sameroff, 2001). This is trend leads to improved outcomes not only for adolescents, but also for college students. Cutrona et al. (1994) found that parental social support continues to positively impact academics with students in college. The sample showed parental social support was a significant predictor of college grade point average.

Parental support in education can be impacted by various factors, including parental level of education and culture (Vitoroulis, Schneider, Vasquez, de Toro, \& Gonzales, 2012). Specifically, parent educational level may impact the amount of academic support parents offer to children (Hill et al., 2004). Highly educated parents likely have high academic expectations for their children, whereas lower educated parents may not (Chen \& Gregory, 2009). High academic expectations for students may then influence the students to adopt similar academic expectations their parents emphasize (Hill et al., 2004). Similarly, culture may impact the level of support parents provide to their children in the school setting. For example, Song et al. (2015) found that perceived parental support was a stronger predictor of achievement goals for Korean adolescents. The authors interpreted this as a cultural difference, as Korean adolescents may feel a strong sense of obligation to their parents due to the sacrifices they have made for their families, and thus perform better academically. Overall, parental support has the power to influence academic achievement in adolescents.

Teacher support. Teacher support plays an integral role in a student's overall development 
and academic success. They spend a great amount of time with children, and thus engage in important interactions and experiences that shape students' attitudes and behaviors. It is imperative for students to feel a sense of connectedness to teachers, and for teachers to show students they know them and care about them. Baker (1999) found that students who have more caring teacherstudent relationships and perceived more teacher support were more likely to ask for and receive help in the classroom. This suggests that supportive, caring teacher relationships foster environments in which students feel they can be successful and learn new things. The need for supportive and positive student-teacher relationships is paramount. These relationships are dyadic and bi-directional, with proximal, interpersonal interactions occurring within a school and classroom setting (Bronfenbrenner \& Morris, 1998). The perception of teacher support, either positive or negative can impact school outcomes for students (Baker, 1999). Teacher support may help to serve as a protective process for students' school performance (Elias \& Haynes, 2008). When students do not feel their teachers care about them personally, then they may become academically unengaged from the classroom. Overall, there have been numerous studies indicating that positive relationships are associated with improved school outcomes (Hughes, Gleason, \& Zhang, 2005; Hughes \& Kwok, 2006).

Teacher support is a variable that can positively influence student academic achievement. Wentzel, Battle, Russel, \& Looney (2010) found that teacher support is an important, positive predictor of students' academic and social motivation. In addition, when students indicated perceived higher levels of social support from teachers, it was positively correlated with gradepoint average (Dubow \& Tisak, 1989). Similarly, positive school relationships between students and teachers were associated with other forms of higher academic achievement (Niebuhr, 1999; Waxman, Huang, Anderson \& Weinstein, 1997). Hamre \& Pianta (2001) found that students who 
had experienced greater levels of teacher support and warmth had better achievement compared to students who had worse relationships. McCormick, O’Connor, Capella \& McClowry (2013) found high quality teacher relationships had a significant impact on math scores. In addition, teacher support has been linked to increased student engagement, which is important for high school students. According to Sedlack, Wheeler, Pullin \& Cusick (1996) as many as $40 \%$ to $60 \%$ of students become disengaged at the high school level. When students perceive teachers as caring and supportive, they are more likely to be engaged within the classroom (Klem \& Connell, 2004). Higher levels of engagement are then associated with higher test scores. Overall, supportive teacher relationships appear to positive impact achievement.

Parental involvement. Schools today are now working on efforts to increase parental involvement as a way in which to build upon the family and school partnership for students (Catsambis, 2001). This construct is difficult to provide a universal definition for, explained by the multifaceted opportunities in which parents can become engaged in their children's educational endeavors. Hill et al. (2004) identify parental involvement as the interactions between parents and school, and the interactions between parents and children that look to benefit students' academic performance. Epstein (1992) established a total of six different types of parental involvement, including: parent practices that establish a positive learning environment at home, parent-school communication regarding student progress and school programs, parent volunteering and participation in the school, parent and school communications regarding learning activities that take place within the home setting, parent involvement in school decision making and parent access to community resources that may bolster students' learning opportunities. Parental involvement examples can include parents attending conferences, or communicating with teachers regarding upcoming tests or projects. 
Parental involvement is a variable that can positively influence student academic achievement. According to Epstein (1992), it is positively related to students' levels of achievement as well as the motivation they have to learn. While research suggests parental involvement is paramount in elementary school aged children, it remains important at the secondary level as well (Catsambis, 2001). Research indicates parental involvement practices continue to be positively associated with student success until the senior year of high school for children (Catsambis, 2001). Of the six identified types of parental involvement, it appears to be less about behavioral regulation or supervision for high school students, and more about advising or guiding academic decisions with students. Jeynes (2012) conducted a meta-analysis to look at the effectiveness of parental involvement programs. It emerged that parental involvement programs were related to higher educational outcomes; while the programs were helpful, the results suggested effect sizes of parents participating in involvement programs were not as impactful as voluntary parental involvement (Jeynes, 2012). In addition, Wang \& Sheikh-Khalil (2013) found school related parental involvement impacted academic functioning in high school students. Similarly, they found that the type of parental involvement may matter - as academic socialization had the strongest positive relation with achievement. School-specific parental involvement has been linked to increased academic achievement (Hill \& Craft, 2003; Mo \& Singh, 2008).

School climate. There is growing support in efforts to focus on school climate, as it has shown to improve educational outcomes not just behaviorally, but academically as well. School climate is known as the quality and character of school life, according to the National School Climate Council. Cohen (2009) explained it as the overarching beliefs, values, and attitudes of those within the school community. It is a construct that shapes and influences the experiences of 
all individuals within a school setting, including students, teachers, parents and administration. A great deal of focus is placed on the support, value, respect and safety within a school setting (Hopson \& Lee, 2011). While there is no universal definition of school climate, it can help to understand the different dimensions that encompass the construct. School climate has been identified as being made up of four dimensions: Safety, teaching and learning, relationships, and environmental-structural components (Cohen et al., 2009). The first dimension, safety, encompasses both physical safety as well as social-emotional safety in a school. It includes clear, concise and consistent rules and consequences within the school environment. Next, teaching and learning components include leadership, professional development, the quality of instruction students receive, and the SEL within the school. The third dimension, relationships, includes components such as respect for diversity, collaboration between the school and community, and the overall "connectedness" of students and staff members. Lastly, the environmental - structural dimension looks at the building facilities, resources, and cleanliness (Cohen et al., 2009). All of these dimensions work together in how school climates are perceived by those within the setting.

School climate is a variable that has been identified as positively influencing academic achievement. A meta-analysis conducted by Wang et al. (1997) indicated that school climate is one of the top influences in improved student achievement. Similarly, MacNeil, Prater \& Busch (2009) found that students have higher achievement when they have a healthy learning environment. There are many studies that lend support to the idea this belief (Zins et al., 2004; Bear et al., 2014; Stewart, 2008). This suggests that a student has to feel a sense of connectedness to others in the classroom, including teachers and peers, in order to learn and demonstrate engagement in and understanding of instruction.

\section{Summary}


With the growing number of children and adolescents displaying symptoms of mental health disorders, as well as the current number of students who are failing to perform proficiently in reading, writing and mathematics, it is imperative that educators focus their efforts on supporting the development of the whole child. Many believe social emotional competencies and academic competencies to be correlated. Students who have better achievement report better overall physical and mental health, as well as opportunities to earn higher paying jobs and overall life satisfaction. Academic achievement could serve as a protective factor for students across the country. However, in order to promote increased achievement, it is necessary to understand the factors that are predictive of higher achievement.

The purpose of the current study is to utilize an ecological systems theory approach to gain a more comprehensive understanding of the relationships among factors that contribute to academic achievement in adolescents. Previous research shows variables, including SEL, selfefficacy, peer social support, teacher social support, parent social support, parental involvement and school climate are individually related to academic achievement. However, there are no studies that look at which of these ecological systems variables are most predictive of achievement. Specifically, with the emphasis on the importance of SEL in learning and school success, the aim of the study is to understand the predictive capabilities related to achievement, and the way in which SEL and achievement are thought to be linked. 


\section{CHAPTER 3 METHOD}

\section{Participants}

The participants of the current study were from a public high school in a suburb of a major metropolitan area in the Midwestern region of the United States. According to the U.S. News and World Report, there are 1,543 students enrolled in the high school. Genders are equally represented, as females and males make up 50\% of the student population. The school is comprised of $70 \%$ Caucasian students, $13 \%$ African American students, 13\% Hispanic students, and 2\% Asian students. More than half of the student body, 53\%, meet criteria as economically disadvantaged. The final sample consisted of 378 participants $(n=176$ males; $46.4 \% ; n=193$ females; 50.9\%; a total of 10 students did not identify gender, $\mathrm{n}=2.6 \%$ ). There were 113 students in the ninth grade $(29.8 \%), 111$ students in the tenth grade $(29.3 \%), 104$ students in the eleventh grade $(27.4 \%)$, and 51 twelfth graders $(13.5 \%)$. The majority of students were Caucasian $(\mathrm{n}=211$, 55.7\%), and the others were African American $(\mathrm{n}=40,10.5 \%)$, Hispanic $(\mathrm{n}=64,16.9 \%)$, Asian/Pacific Islander $(n=10,2.6 \%)$, Middle Eastern $(n=5,1.3 \%)$ and Mix-Raced $(n=44$, 11.6\%). Demographics were comparable to the overall student population.

\section{Measures}

Demographics. Students completed a short demographic survey containing questions pertaining to grade, age, gender, socio-economic status, and ethnicity. To measure socio-economic status, students were asked to circle yes or no to the question, "Do you receive free or reduced lunch?" The response was coded as Yes (1) and No (0). It is important to note that the larger number means lower SES in this data set.

Academic achievement. Students reported their most recent grades in their four core classes (language arts, math, science, social studies). Specifically, they were asked to circle A, A, B+, B, B-, C+, C, C-, D+, D, D-, E or N/A for each grade. Students selected N/A if they did not 
have one of the four identified core classes. Grades were coded by 11 (A) to (0) E. They were also asked to note the grades that they typically achieve, with the prompt, "What grades do you typically receive?" Students circled one of the following responses: Mostly As, Mostly As and B, Mostly Bs, Mostly Bs and Cs, Mostly Cs, Mostly Cs and Ds, Mostly Ds, Mostly Ds and Es, and Mostly Es. Responses were coded between Mostly As (9) and Mostly Es (1).

Social-emotional learning (SEL). The Social Emotional Learning Scale (SELS) was used to measure students' perceptions of SEL (Coryn, Spybrook, Everygreen, \& Blinkiewicz, 2009). The SELS is a 20-item questionnaire designed to look at three different factors of the social and emotional learning, as defined by the CASEL categorizations. Each item includes five possible response options ranging from strongly disagree to strongly agree. The three domains are Task Articulation (TA), Peer Relationships (PR) and Self-Regulation (SR). The items in the Task Articulation subscale focus on the CASEL identified SEL component of responsible decision making. The Peer Relationships subscale focuses on the CASEL components of social awareness and relationship skills. The Self-Regulation subscale focuses on items related to the CASEL components of self-awareness and self-management (Coryn et al., 2009). Examples of items from the SELS include, "I understand the feelings expressed by others," "I keep track of my progress toward a goal," and "I figure out different solutions to personal problems." A total score was computed by summing all items on each subscale; higher total scores reflect that the individual has the identified social-emotional learning attribute.

The reliability of the three subscales on the SELS was assessed using Cronbach's alpha. The authors found the estimate for the Task Articulation scale to be $\alpha=.69$; the Personal Relationship scale's $\alpha=.80$; the Self-Regulation reliability was $\alpha=.80$ (Coryn et al., 2009). The reliability of the total scale was found to be $\alpha=.93$ (Totan, 2011). Internal consistency reliability 
coefficients for the SELS have been found to range between .72 and .82 for test-retest reliability and .78 and .87 for sub-coefficients (Arslan, 2015). In the current sample, the Cronbach's alpha internal consistency reliability coefficient was .92 for the total scale.

Self-efficacy. The Self-Efficacy Questionnaire for Children (SEQ - C) was used to measure students' own self-efficacy (Muris, 2001). The SEQ-C is a 24-item questionnaire designed to look at three different domains of self-efficacy, including social self-efficacy (perceptions on peer relationships and assertiveness), academic self-efficacy (the ability to fulfill academic expectations, manage the learning processes, and master academic subjects), and emotional self-efficacy (the ability to manage negative emotions). The responses are scored using a 5-point likert scale ranging from $1=$ not at all to $5=$ very well. Examples of items from the SEQ - C include "How well can you pay attention during every class," "How well can you succeed in staying friends with other children," and "How well do you succeed in not worry about things that might happen?"

The SEQ - C seems to be a valid and reliable questionnaire in which students' perceptions of self-efficacy are gathered. The internal consistency reliability of the SEQ-C had a total selfefficacy score of .88; the Cronbach's $\alpha$ for the subscale scores was between .85 and .88 . In addition, Muris (2001) found the subscales of the SEQ - C to be significantly intercorrelated. Specifically, the emotional self-efficacy subscale correlated with the social self-efficacy $(.40 ; p<$ $.001)$; emotional self-efficacy was correlated with academic self-efficacy $(.41 ; p<.001)$. However, it should be noted the correlation between academic self-efficacy and social self-efficacy were lower $(.17 ; p<.005)$. Lastly, there were significant gender differences found with the SEQ - C. Girls were found to report lower levels of overall self-efficacy, specifically due to lower levels of perceived emotional self-efficacy than boys (Muris, 2001). The alpha was .91 in the current 
sample.

Peer, parent, and teacher support. In order to survey students' perceived levels of parent, teacher, and peer support, the Child and Adolescent Social Support Scale (CASSS) was used (Malecki, Demaray, \& Elliot, 2000). This particular survey was modeled after Tardy's multidimensional model of social support (Malecki et al., 2000). This is a 60-item, multi-dimensional survey that looks to explore perceived support from areas including parents, teachers, classmates, close friend, and school with children in third through twelfth grades. The initial model was based on four subscales (parents, teachers, classmates, and friends) and consisted of 40-items (Malecki et al., 1999). However, there have been changes to the 1999 version, including an addition of a subscale (School) and rewording of items. The rating scale includes a 6-point Likert Scale for responses, ranging from 1 (Never) to 6 (Always). For the purpose of this study, three subscales were used: peer support, parent support, and teacher support.

Students completed the peer subscale of the CASSS to measure perceived levels of classmate support. This 12-item subscale includes items such as My classmates... "treat me nicely," "give me good advice," and "tell me good job when I've done something well." The parent subscale of the CASSS was used to measure perceived levels of parent support. This subscale consists of 12-items. Example items include My Parent(s)... "show they are proud of me," "help me solve problems by giving me information," and "take time to help me decide things." The teacher subscale of the CASSS was used to measure perceived levels of teacher support. This subscale consists of 12-items that include My Teachers... "care about me," "help me solve problems by giving me information," and "nicely tell me when I make mistakes."

The CASSS has been found to demonstrate appropriate reliability and validity scores. The reliability for the overall scale was found to be $\alpha=.96$. Reliability coefficients (Cronbach's $\alpha$ ) 
were found to range from $\alpha=.92$ to $\alpha=.95$ for the five subscales. The test-rest reliability coefficients range from $.75-.78$ for the total frequency score, and $.58-.74$ for the frequency subscales. In addition, the test-retest reliability for the Total importance scale is .70 , with the importance subscales ranging from .60 - .76. In terms of validity, the CASSS has been correlated with the Social Support Scale for Children. The correlation between the two was .70 (Malecki et al., 2000). The Cronbach's alpha for peer support was .96 , while parent support was .96, and teacher support was .97 .

Parental involvement. The Commitment to Achievement Measure (Paulson, 1994) was used to measure students' perceptions on parent involvement. This 22-item scale looks at parent involvement in their children's academics and schooling. Students are given a five-factor Likert rating scale, ranging from Very Unlike, More Unlike than Like, Neither Like nor Unlike, More Like than Unlike, Very Unlike. Sample items include "My parent usually does not go to school functions," "My parent usually goes to parent-teacher conferences," and "Hard work is very important to my parent." Items are designed to explore students' perceptions of specific dimensions of parental involvement, including, achievement values, interest in schoolwork, and involvement in school functions. It is important to note that the term "mother" in the original measure was changed to "parent/guardian" for the purpose of this study. In terms of reliability, Cronbach's alpha for the adolescent report of maternal involvement was found to be .79 for the achievement value subscale, .77 for the interest in schoolwork subscale, and .71 for the involvement in school functions (Paulson, 1994). In the current study, Cronbach's alpha was .82 for the total scale.

School climate. The Delaware School Climate Survey - Students (DSCS-S) developed by Bear et al. (2014) was used to measure students' perceptions of school climate. There are a total 
of 29 items on this measure, which focuses on eight subscales of school climate, including Teacher-Student Relations (five items), Student-Student Relations (four items), School Safety (three items), Clarity of Expectations (four items), Fairness of School Rules (four items), Respect for Diversity (three items), Student Engagement Schoolwide (five items), and Bullying Schoolwide (four items), which all yields a Total School Climate measure. Students select from four response options, ranging from Disagree a Lot, Disagree, Agree, and Agree a Lot. A revised version of the DCSC - S was developed in 2013; the revised scale will be used in the study.

Internal consistency coefficients of the DSCS-S ranged from .76 to .87 (Bear et al., 2011).

The subscales for Teacher-Student Relations and Student-Student Relations had the highest alpha coefficients, whereas the subscale for Clarity of Expectations had the lowest reliability coefficients (Bear et al., 2014). In terms of validity, the DSCS-S had moderate correlations when compared to suspension and expulsion rates, and academic achievement (Bear et al., 2014). The Cronbach's alpha was .92 for this current study.

\section{Procedure}

After approval from Wayne State University's Institutional Review Board (IRB), data was collected throughout the students' academic center classes at the selected high school. A total of 4 hours of Academic Center teachers and all students enrolled in an Academic Center class, were contacted. The Academic Center classes are a mixture of students from every grade, and included both general education and special education students. The examiner explained data collection would occur during the first $20-30$ minutes of their class period in the cafeteria. The Academic Center class was selected so as not to interrupt instruction in core or elective classes.

Parents were sent supplemental information forms via first-class mail two weeks prior to data collection. These letters described the nature of the study and what type of information was 
to be collected. The letters provided parents the opportunity to request an electronic copy of the surveys for their own viewing purposes and/or to refuse their child's participation. Parents could refuse their child's participation by emailing the Principal Investigator (PI), calling the school, or returning a tear-off form to the school. Students whose parents were not able to be contacted or who decline their participation in the study will be given an alternative task during data collection. A total of 10 students were requested by their parents to not participate in the study.

The PI entered the high school with blank surveys contained in manila envelopes, and distributed the surveys in the cafeteria to the group of students during their Academic Center class period. Students were presented with oral assent forms before being asked to participate in the study. The PI informed parents, teachers and students that participation in the study was voluntary, and that all data collected would remain anonymous. The PI provided the students in the cafeteria with instructions that directed participating students to take a blank survey set from the manila envelope, and then place the survey in a second manila envelope when completed. Students had the option of receiving a piece of candy after completing, attempting to complete the survey, or not completing the survey.

\section{Data Analysis}

Data collected was entered, coded, and analyzed using Statistical Package for the Social Science (SPSS) software. SPSS was utilized to examine the data, including conducting frequency distributions of demographic information. With respect to specific research hypotheses and questions, inferential statistical analyses were used. An alpha criterion of 0.05 was utilized to examine statistical significance. The following table (Table 1) presents the research questions, hypotheses, variables used and proposed statistical analysis. 
Table 1

Research Questions

Research Question 1:

How strongly correlated are social-emotional learning and academic achievement?

\begin{tabular}{l|l|l}
\hline Research Hypotheses & Variables & Statistical Analyses \\
\hline $\begin{array}{l}\text { H1: Social-emotional learning and } \\
\text { academic achievement will be highly } \\
\text { correlated }\end{array}$ & $\begin{array}{l}\text { - Social-emotional learning } \\
\text { - Academic achievement }\end{array}$ & $\begin{array}{l}\text { Pearson Correlation } \\
\text { Analysis }\end{array}$ \\
\hline
\end{tabular}

Research Question 2:

What intrapersonal variables (self-efficacy and social and emotional learning) are most predictive of academic achievement?

\begin{tabular}{|c|c|c|}
\hline Research Hypotheses & Variables & Statistical Analyses \\
\hline $\begin{array}{l}\text { H1: The intrapersonal variables (self- } \\
\text { efficacy and social emotional } \\
\text { learning) will explain a statistically } \\
\text { significant proportion of variance in } \\
\text { high school student academic } \\
\text { achievement. }\end{array}$ & $\begin{array}{l}\text { Predictor variables } \\
\text { Demographics (Step 1) } \\
\text { Intrapersonal Variables (Step } \\
\text { 2): } \\
\text { - Self-efficacy } \\
\text { - Social emotional learning } \\
\text { Criterion variable } \\
\text { - Academic Achievement }\end{array}$ & $\begin{array}{l}\text { Hierarchical Linear } \\
\text { Regression Analysis }\end{array}$ \\
\hline
\end{tabular}

Research Question 3:

What microsystem variables (peer support, parent support, teacher support, parental involvement, school climate) are most predictive of academic achievement?

\begin{tabular}{l|l|l}
\hline Research Hypotheses & Variables & Statistical Analyses \\
\hline $\begin{array}{l}\text { H2: The microsystem variables (peer } \\
\text { support, parent support, teacher } \\
\text { support, parental involvement, school } \\
\text { climate) will explain a statistically } \\
\text { significant proportion of variance in } \\
\text { high school student academic } \\
\text { achievement. }\end{array}$ & Pemographics (Step 1) & $\begin{array}{l}\text { Hierarchical Linear } \\
\text { Regression Analysis }\end{array}$ \\
& $\begin{array}{l}\text { - Perceived peer support } \\
\text { - Perceived parent support } \\
\end{array}$ & \\
& $\begin{array}{l}\text { - Perceived teacher support } \\
\text { - Parental involvement }\end{array}$ & \\
& - School climate & \\
& Criterion variable & \\
& - Academic Achievement & \\
\hline
\end{tabular}

Research Question 4:

In a combined model, do the microsystem variables (peer support, parent support, teacher support, parental involvement, school climate) and self-efficacy significantly predict achievement above and beyond social-emotional learning?

\begin{tabular}{l|l|l}
\hline Research Hypotheses & Variables & Statistical Analyses \\
\hline
\end{tabular}




\begin{tabular}{|c|c|c|}
\hline $\begin{array}{l}\text { H3: Intrapersonal variables (self- } \\
\text { efficacy and social emotional } \\
\text { learning) will explain more variance } \\
\text { in high school student academic } \\
\text { achievement than microsystem } \\
\text { variables (perceived peer support, } \\
\text { perceived parent support, perceived } \\
\text { teacher support, parental } \\
\text { involvement, and school climate). }\end{array}$ & $\begin{array}{l}\text { Predictor variables } \\
\text { - Demographics (Step 1) } \\
\text { - Social emotional learning } \\
\text { (Step 2) } \\
\text { - Self-efficacy (Step 3) } \\
\text { Microsystem Variables (Step } \\
\text { 4): } \\
\text { - Perceived peer support } \\
\text { - Perceived parent support } \\
\text { - Perceived teacher support } \\
\text { - Parental involvement } \\
\text { - School climate } \\
\text { Criterion variable } \\
\text { - Academic Achievement }\end{array}$ & $\begin{array}{l}\text { Hierarchical Linear } \\
\text { Regression Analysis }\end{array}$ \\
\hline
\end{tabular}




\section{CHAPTER 4 RESULTS}

The purpose of this study was to investigate the roles of select intrapersonal and microsystem factors in adolescents' academic achievement. In addition, social and emotional learning was examined to determine how predictive it was of achievement compared to intrapersonal and microsystem level variables. The distribution of the sample was normal. There was little missing data from this sample. Mean substitution by key demographics was used for the small amount of data that was missing. In all of the analyses, a criterion alpha level of .05 was used to determine statistical significance.

Preliminary analyses involved a series of Analysis of Variance (ANOVA) tests for gender, grade-level, socio-economic status (SES), and race differences in the study variables. These analyses revealed gender, SES, race and grade differences in about half of the variables. Specifically, there was a statistically significant difference found in self-efficacy by gender $[\mathrm{F}(1$, $359)=8.08, p<.01]$. In addition, there were significant differences found in school climate by gender $[\mathrm{F}(1,356)=9.00, p<.01]$, parent support by gender $[\mathrm{F}(1,352)=15.47, p<.001]$, teacher support by gender $[\mathrm{F}(1,352)=8.18, p<.01]$ and peer support by gender $[\mathrm{F}(1,348)=7.91, p<$ .01]. Next, there were statistically significant differences found in parent involvement by SES [F(1, $360)=9.96, p<.01]$, parent support by $\operatorname{SES}[\mathrm{F}(1,360)=7.90, p<.01]$, and academic achievement by $\operatorname{SES}[\mathrm{F}(1,374)=28.12, p<.001]$. Another statistically significant difference was found in academic achievement by $\operatorname{race}[\mathrm{F}(5,366)=4.14, p<.01]$. Lastly, there were significant differences determined by a one-way ANOVA for social-emotional learning (SEL) by grade [F(3, $372)=4.55, p<.01]$, self-efficacy by grade $[\mathrm{F}(3,367)=2.82, p<.05]$, school climate by grade

$[\mathrm{F}(3,364)=5.17, p<.01]$, teacher support by grade $[\mathrm{F}(3,359)=2.99, p<.05]$, and academic achievement by grade $[\mathrm{F}(3,373)=2.63, p=.05]$.

These differences were not the focus of the study and thus were controlled for in subsequent 
analyses, which involved hierarchical regression analysis with gender, grade, socio-economic status and race entered at step 1 of each analysis. Means and standard deviations for primary variables are in Table 2 and correlations among these variables are included in Table 3.

Table 2

Descriptive Statistics and Cronbach's Alphas for Study Variables

\section{$\underline{\text { Range }}$}

\begin{tabular}{lcccccc} 
Variables & Missing & $\alpha$ & Mean & $S D$ & Min & Max \\
\hline Academic Achievement & 1 & n/a & 7.36 & 2.83 & 0.00 & 11.00 \\
Social Emotional Learning & 3 & .92 & 3.79 & 0.62 & 1.00 & 5.00 \\
Self-Efficacy & 8 & .91 & 3.37 & 0.65 & 1.00 & 5.00 \\
Peer Support & 20 & .96 & 3.83 & 1.26 & 1.00 & 6.00 \\
Parent Support & 16 & .96 & 4.41 & 1.31 & 1.00 & 6.00 \\
Teacher Support & 16 & .97 & 4.09 & 1.30 & 1.00 & 6.00 \\
Parental Involvement & 16 & .82 & 3.69 & 0.57 & 1.59 & 5.99 \\
School Climate & 11 & .92 & 2.60 & 0.44 & 1.18 & 3.79 \\
\hline
\end{tabular}

Table 3

Pearson's Product-Moment Correlation Matrix: All Study Variables

\begin{tabular}{|c|c|c|c|c|c|c|c|}
\hline & 1 & 2 & 3 & 4 & 5 & 6 & 7 \\
\hline 1. Academic Achievement & - & & & & & & \\
\hline 2. Social Emotional Learning & $.20 * *$ & - & & & & & \\
\hline 3. Self-Efficacy & $.30 * *$ & $.61 * *$ & - & & & & \\
\hline 4. Peer Support & -.01 & $.36 * *$ & $.36 * *$ & - & & & \\
\hline 5. Parent Support & $.15^{* *}$ & $.31 * *$ & $.37 * *$ & $.39 * *$ & - & & \\
\hline 6. Teacher Support & $.23 * *$ & $.39 * *$ & $.43 * *$ & $.40 * *$ & $.39 * *$ & - & \\
\hline 7. Parental Involvement & $.29 * *$ & $.39 * *$ & $.43 * *$ & $.21 * *$ & $.53 * *$ & $.32 * *$ & - \\
\hline 8. School Climate & $.14 * *$ & $.39 * *$ & $.49 * *$ & $.35 * *$ & $.28 * *$ & $.52 * *$ & $.21 * *$ \\
\hline
\end{tabular}




\section{Research Question 1: How strongly correlated are social-emotional learning and academic achievement?}

In examining the degree to which SEL and academic achievement were correlated, a simple Pearson correlation analysis was run. The results show a statistically significant but low correlation between SEL and academic achievement/overall GPA $(r=.20, p<.01)$. Additionally, the three subscales of SEL were examined to see if results varied for the three constructs compared to overall SEL. There were significant, but weak, correlations between academic achievement and selfregulation $(\mathrm{r}=.20, p<.001$, task articulation $(\mathrm{r}=.20, p<.001)$, and personal relationships $(\mathrm{r}=$ $.14, p<.01)$. See Tables 4 and 5 .

Next, correlations were run to determine associations between subscales of SEL and grades earned in each of the four core classes (math, language arts, social studies, science). Results revealed that most all correlations were statistically significant but low in strength, regardless of the specific subscale of SEL and the type of classes. As this was no greater than the correlation for the total SEL scale, only the overall academic achievement score/overall GPA and the overall SEL scores were used.

In addition, given these demographic differences, a hierarchical regression analysis was conducted to examine the association between total SEL and academic achievement controlling for these demographic differences. A total of $9 \%$ of variance in academic achievement was accounted for by these demographic variables $(\mathrm{F}=8.93$, $\mathrm{df}=4,359, p<.001)$. Specifically, two demographic variables, SES $(\beta=-.25, p<.001)$ and grade $(\beta=.12, p<.05)$, were the significant contributors. However, at the second step, SEL was also found to be statistically significant $(\beta=$ $.23, p<.001)$ above and beyond the explanation of variance by the demographic variables entered at the initial step. SEL explained an additional 5\% of the variance of academic achievement at the 
second step, significantly above and beyond what accounted for at step one $\left(R^{2}\right.$ change $=.05, p<$ .001). Grade did not remain significant at step 2 once in the presence of SEL, but SES did. Interestingly, SEL and SES had similar BETA weights, suggesting similar amounts of contribution in explaining the variance. In the overall model, a total of $14 \%$ of the variance of academic achievement was explained by demographics and SEL. See Table 6.

Table 4

Pearson's Product-Moment Correlation Matrix: Academic Achievement \& Social Emotional Learning and SEL Subscales

\begin{tabular}{|c|c|c|c|c|}
\hline & 1 & 2 & 3 & 4 \\
\hline 1. Academic Achievement & - & & & \\
\hline 2. Social Emotional Learning & $.20 * * *$ & - & & \\
\hline 3. Task Articulation (SEL Subscale) & $.20 * * *$ & $.89 * * *$ & - & \\
\hline 4. Personal Relationships (SEL Subscale) & $.14 * *$ & $.92 * * *$ & $.72 * * *$ & - \\
\hline 5. Self Regulation (SEL Subscale) & $.20 * * *$ & $.93 * * *$ & $.77 * * *$ & $.78 * * *$ \\
\hline
\end{tabular}




\section{Table 5}

Pearson's Product-Moment Correlation Matrix: Class Specific Academic Achievement \& Social Emotional Learning and SEL Subscales

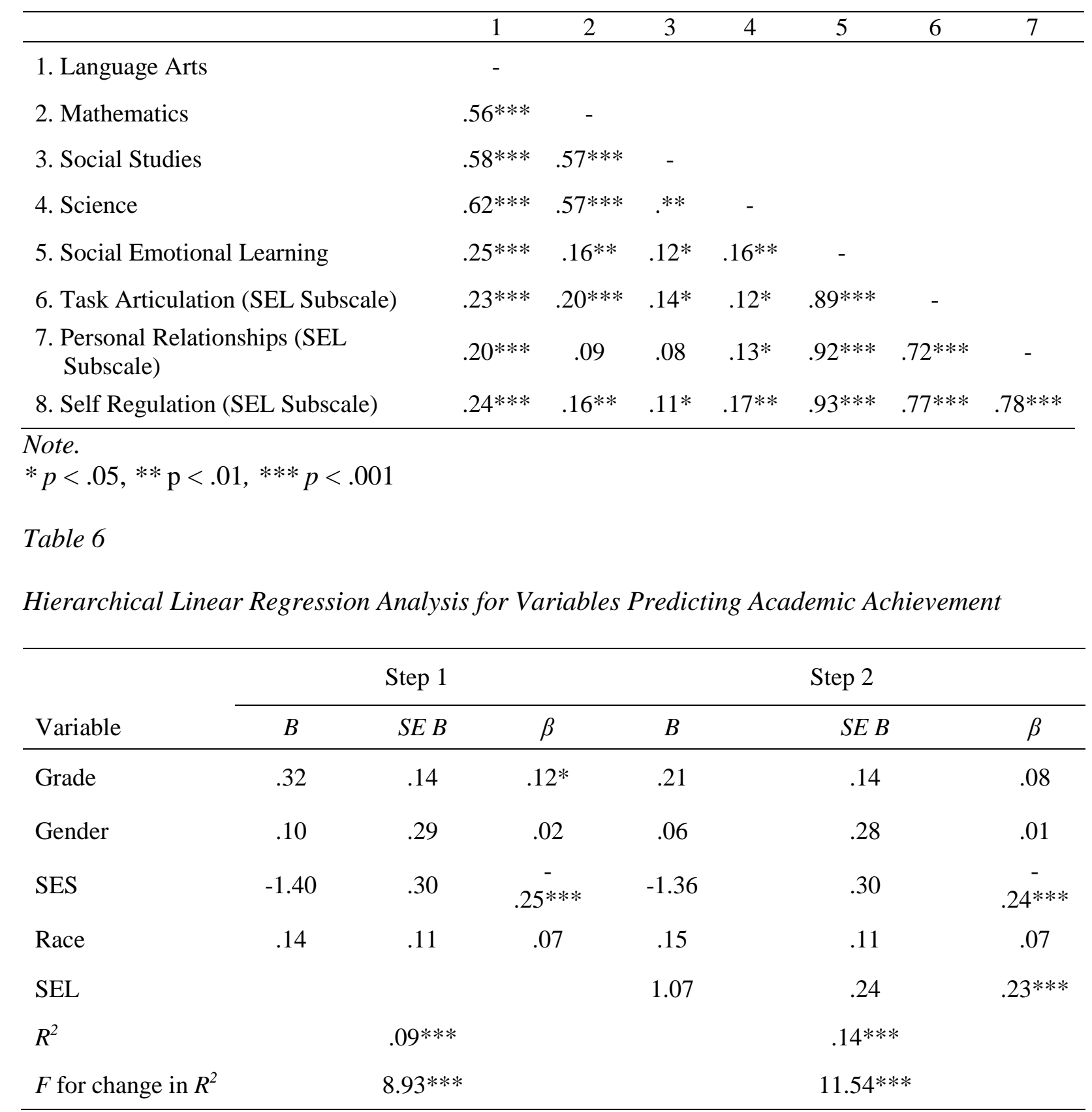

Note.

$* p<.05, * * \mathrm{p}<.01, * * * p<.001$ 


\section{Research Question 2: What intrapersonal variables (self-efficacy and social and emotional learning) are most predictive of academic achievement?}

Hierarchical regression analysis was conducted to determine the degree to which the intrapersonal factors of self-efficacy and social and emotional learning explained variance in academic achievement. The four demographic variables were again entered at step 1. Results indicated that two of the variables, SES and grade, made significant contributions to the variance in academic achievement (Grade $\beta=.11, p<.05$ and SES $\beta==.25, p<.01$ ), and explained a total of $9 \%$ of the variance $(\mathrm{F}=8.82, \mathrm{df}=4,349, p<.001)$. At step 2, social and emotional learning and self-efficacy were entered, and while SES continued to be significant $(\beta=-.23, p<.001)$, grade was no longer found to be significant in terms of demographics. The introduction of intrapersonal variables increased the variance by an additional $8 \%\left(R^{2}\right.$ change $\left.=.08, p<.001\right)$. Self-efficacy was found to be a significant contributor $(\beta=.21, p<.01)$ above and beyond that accounted for at the first step. However, SEL was not significant when in the presence of selfefficacy. Self-efficacy and SES had similar beta weights, suggesting similar amounts of contribution to explaining the variance in achievement. A total of $17 \%$ of the variance was explained by demographic and intrapersonal variables. See Table 7. 
Table 7

Summary of Hierarchical Linear Regression Analysis for Variables Predicting Academic Achievement (Demographics and Intrapersonal Variables)

\begin{tabular}{|c|c|c|c|c|c|c|}
\hline \multirow[b]{2}{*}{ Variable } & \multicolumn{3}{|c|}{ Step 1} & \multicolumn{3}{|c|}{ Step 2} \\
\hline & $B$ & $S E B$ & $\beta$ & $B$ & $S E B$ & $\beta$ \\
\hline Grade & .30 & .14 & $.11^{*}$ & .17 & .14 & .06 \\
\hline Gender & .13 & .29 & .02 & .28 & .28 & .05 \\
\hline SES & -1.39 & .30 & $.25^{-}+* *$ & -1.28 & .29 & $\begin{array}{c}- \\
.23 * * *\end{array}$ \\
\hline Race & .16 & .11 & .08 & .17 & .10 & .08 \\
\hline SEL & & & & .47 & .30 & .10 \\
\hline Self-Efficacy & & & & .95 & .29 & $.21 * *$ \\
\hline$R^{2}$ & & $.09 * * *$ & & & $.17 * * *$ & \\
\hline $\begin{array}{l}F \text { for change in } \\
R^{2}\end{array}$ & & $8.82 * * *$ & & & $11.92 * * *$ & \\
\hline
\end{tabular}

Research Question 3: What microsystem variables (peer support, parent support, teacher support, parental involvement, school climate) are most predictive of academic achievement?

To determine the degree to which microsystem level variables, including school climate, parental involvement, parent support, teacher support, and peer support, explained variance in academic achievement, a hierarchical regression analysis was run. As in the prior research question, the same proportion of variance was explained at steps 1 and 2 . At step 1 , the demographics accounted for a total of $9 \%$ of the variance in academic achievement $(\mathrm{F}=9.635$, $\mathrm{df}$ $=4, p<.001)$. Specifically grade $(\beta=.11, p<.05)$ and $\operatorname{SES}(\beta=-.28, p<.001)$ were found to be the significant demographic contributors to the variation in academic achievement. 
At Step 2, SES continued to be significant $(\beta=-.24, p<.001)$, however grade was no longer a significant contributor. The microsystem variables that statistically contributed to the variation in academic achievement included parental involvement $(\beta=.22, p<.001)$ and teacher support $(\beta=.21, p<.002)$. SES, parental involvement and teacher support all had nearly the same beta weights, suggesting similar amounts of contribution to explaining variance in achievement. School climate, parent support and peer support were not found to be significant contributors. The introduction of the microsystem level variables explained an additional $8 \%$ of the total variance in academic achievement at the second step $\left(R^{2}\right.$ change $\left.=.08, p<.001\right)$, which accounted for above and beyond what the demographics contributed to the variance in the initial step. Together, demographics and microsystem level variables accounted for a total of $17.2 \%$ of the variance in academic achievement. See Table 8. 
Table 8

Summary of Hierarchical Regression Analysis for Variables Predicting Academic Achievement (Demographic \& Microsystem Variables)

\begin{tabular}{|c|c|c|c|c|c|c|}
\hline \multirow[b]{2}{*}{ Variable } & \multicolumn{3}{|c|}{ Step 1} & \multicolumn{3}{|c|}{ Step 2} \\
\hline & $B$ & $S E B$ & $\beta$ & $B$ & $S E B$ & $\beta$ \\
\hline Grade & .29 & .14 & $.11^{*}$ & .24 & .14 & .09 \\
\hline Gender & .10 & .29 & .02 & .12 & .29 & .02 \\
\hline SES & -1.53 & .30 & $-.28 * * *$ & -1.32 & .30 & $-.24 * * *$ \\
\hline Race & .12 & .11 & .06 & .10 & .11 & .05 \\
\hline Peer Support & & & & -.23 & .12 & -.11 \\
\hline Parent Support & & & & -.09 & .15 & -.04 \\
\hline Teacher Support & & & & .44 & .13 & $.21 * *$ \\
\hline Parental Involvement & & & & 1.10 & .31 & $.22 * * *$ \\
\hline School Climate & & & & .00 & .38 & .00 \\
\hline$R^{2}$ & & $.09 * * *$ & & & $.17 * * *$ & \\
\hline$F$ for change in $R^{2}$ & & $9.64 * * *$ & & & $8.76^{* * *}$ & \\
\hline
\end{tabular}

Note.

$* p<.05, * * \mathrm{p}<.01, * * * p<.001$

Research Question 4: In a combined model, do the microsystem variables (peer support, parent support, teacher support, parental involvement, school climate) and self-efficacy significantly predict achievement above and beyond social-emotional learning?

Lastly, a hierarchical regression analysis was run to determine in a combined model which, if any variables, explained variance in achievement above and beyond SEL. Demographic variables were entered and controlled for at step 1 of the regression $\left(R^{2}=.09, p<.001 ; \mathrm{F}=9.50\right.$, $\mathrm{df}=4, p<.001)$, and it was again grade $(\beta=.11, p<.05)$ and $\operatorname{SES}(\beta=-.28, p<.001)$ that surfaced as the significant contributors to variance in academic achievement in the initial step. 
At the second step, SEL $(\beta=.24, p<.001)$ and $\operatorname{SES}(\beta=-.26, p<.001)$ were found to be significant contributors to variance. The introduction of SEL accounted for an additional $6 \%$ of variance at the second step $\left(R^{2}=.15, p<.001 ; \beta=.24, p<.001\right)$, above and beyond the explained variance in the initial step. While SES continued to be statistically significant at the second step, grade was no longer significant. A total of $15 \%$ of the variance was explained by the variables in the second step.

Next, self-efficacy was introduced at the third step. Self-efficacy $(\beta=.19, p<.005)$ and SES $(\beta=-.25, p<.001)$ were found to be statistically significant contributors at this step in the model. SEL was no longer found to be significant when self-efficacy was included in the model. SES had the largest beta weight suggesting it contributed to the variance to a greater degree than self-efficacy. Although statistically significant, with the addition of the self-efficacy variable at step 3 , there was only a $1 \%$ increase in variance $(\mathrm{F}=12.00, \mathrm{df}=6, p<.001)$. The third step accounted for a total of $16 \%$ of the variance in academic achievement.

Lastly, an additional $4 \%$ of the variance was explained by the addition of the microsystem level variables $\left(R^{2}\right.$ change $\left.=.20, p<.01 ; \mathrm{F}=8.78, \mathrm{df}=11, p<.001\right)$. The variables that surfaced as significant, and thus significantly explaining variance in academic achievement, at the fourth step in this full model were SES $(\beta=-.24, p<.001)$, self-efficacy $(\beta=.18, p<.05)$, parental involvement $(\beta .17, p<.01)$, teacher support $(\beta=.17, p<.01)$, and peer support $(\beta=-.14, p<$ .05). This suggests microsystem variables from parents, peers and teachers all mattered at the final step, above and beyond other variables. Variables that were not found to be significant when examining the impact of all variables on academic achievement included SEL, parent support, and school climate. A total of $20 \%$ percent of the variance in achievement was explained by this full model when demographics, intrapersonal variables, and microsystem variables were all added into 
the analysis. This suggests that the variability in academic achievement was accounted for above and beyond when looking at a combination of variables through the ecological lens, compared to simply looking at it through the singular lens of microsystem variables only or intrapersonal variables only. See Table 9.

Table 9

Hierarchical Linear Regression Analysis - Demographic, Intrapersonal, and Microsystem Variables on Academic Achievement

\begin{tabular}{|c|c|c|c|c|c|c|c|c|c|c|c|c|}
\hline \multirow[b]{2}{*}{ Variable } & \multicolumn{3}{|c|}{ Step 1} & \multicolumn{3}{|c|}{ Step 2} & \multicolumn{3}{|c|}{ Step 3} & \multicolumn{3}{|c|}{ Step 4} \\
\hline & $B$ & $S E B$ & $\beta$ & $B$ & $S E B$ & $\beta$ & $B$ & $S E B$ & $\beta$ & $B$ & $S E B$ & $\beta$ \\
\hline Grade & .29 & .14 & .11 & .18 & .14 & .07 & .17 & .14 & .06 & .18 & .14 & .07 \\
\hline Gender & .09 & .29 & .02 & .05 & .28 & .01 & .21 & .28 & .04 & .10 & .28 & .02 \\
\hline SES & -1.52 & .30 & $-.28 * * *$ & -1.46 & .29 & $-.26^{* * *}$ & -1.39 & .29 & $-.25^{* * *}$ & -1.30 & .30 & $-.24^{* * *}$ \\
\hline Race & .12 & .11 & .06 & .13 & .11 & .06 & .14 & .11 & .07 & .10 & .10 & .05 \\
\hline Social Emotional Learning & & & & 1.08 & .23 & $.24 * * *$ & .53 & .30 & .12 & .40 & .30 & .09 \\
\hline Self-Efficacy & & & & & & & .84 & .29 & $.19 * *$ & .77 & .30 & $.18^{*}$ \\
\hline Peer Support & & & & & & & & & & -.31 & .13 & $-.14^{*}$ \\
\hline Parent Support & & & & & & & & & & -.14 & .14 & -.95 \\
\hline Teacher Support & & & & & & & & & & .37 & .13 & $.17^{* *}$ \\
\hline Parental Involvement & & & & & & & & & & .82 & .31 & $.17 * *$ \\
\hline School Climate & & & & & & & & & & -.41 & .39 & -.06 \\
\hline$R^{2}$ & & $.09 * * *$ & & & $.15^{* * *}$ & & & $.16^{* *}$ & & & $.20^{* *}$ & \\
\hline$F$ for change in $R^{2}$ & & $9.50^{* * *}$ & & & $12.39 * * *$ & & & $12.00^{* * *}$ & & & $8.78^{* * *}$ & \\
\hline
\end{tabular}




\section{CHAPTER 5 DISCUSSION}

With the decline in proficient academic skills, as well as the increase of mental health disorders in children and adolescents, there is a significant need to better support and teach students in the school setting. This support encompasses fostering a multitude of skills - including not only academic skills but social and emotional skills as well. The combination of differing skills is believed to positively impact the success of individuals, as they learn to navigate the world around them. Social and emotional learning (SEL) encompasses a critical set of skills for children and adolescents to master, skills that have demonstrated a plethora of positive effects (Durlak et al., 2011). Prior research has indicated that students with developed social and emotional skills have better outcomes compared to students with less developed skills (Durlak et al., 2011). Specifically, these positive outcomes associated with SEL programming include increased academic achievement and a reduction in mental health concerns (Neil \& Christensen, 2007; Durlak et al., 2011). Increased academic achievement is also associated with greater outcomes over time for individuals. In order to best help adolescents succeed in entering adulthood in positive, productive ways, it is imperative to identify strategies in which to help them maximize their academic achievement efforts.

Based on this information, one of the major aims of the current study was to identify whether several key variables, carefully selected across one's ecology, would better explain variance in academic achievement conducted in previous studies. There have been few, if any, studies that have looked at the potential ways in which this unique combination of variables can explain achievement. The specific combination of variables that appeared to significantly contribute above and beyond to high school students' academic achievement included SEL, selfefficacy, socioeconomic status (SES), peer support, teacher support, and parental involvement. 
These results support individual findings from previous literature, in which variables have been identified as significant contributors in explaining variance in achievement (Durlak et al., 2011; Sirin, 2005; Chiu \& Xihua, 2008; Galyon et al., 2012; Schunk et al., 2010; Wentzel et al., 2004; Hughes et al., 2005; Wang \& Sheikh-Khalil, 2012).

There were various themes that emerged in the study. To begin with, SEL was examined due to a large amount of evidence linking it to increased academic achievement (Durlak et al., 2011; Zins et al., 2004; Johnson \& Johnson 2000). First, SEL played a significant role in explaining variance in academic achievement. In addition, SEL and academic achievement were found to have a small, but significant relationship. While the aforementioned selected variables were shown to significantly explain variance in academic achievement, SEL was hypothesized to be the biggest contributor. However, SEL did not transpire to be as strong a contributor as originally believed. Although significant, the relationship between social-emotional learning and academic achievement was rather weak. In addition, SEL was no longer significant once entered in combination with other study variables. This suggests that while SEL played a role, other variables appeared to play stronger roles in understanding academic achievement.

One possible explanation for the somewhat limited role of SEL may be explained by the large amount of skills within the SEL construct. Criticism of SEL is that it is an umbrella-like term that encompasses many different types of skills (Hoffman, 2008). As SEL encompasses a broad, multi-faceted set of skills, it may be too amorphous to confidently determine which skills are being measured within the specific construct of SEL. The SEL measure was purposely selected as there are few tools that look to examine all highlighted competency areas as identified by Collaborative for Academic, Social, and Emotional Learning (CASEL). Even within the subscales of the Social Emotional Learning Scale (SELS) it may have been difficult to truly capture the individualized 
constructs, as two of the subscales combined two components. The idea of SEL being too challenging to operationalize due to the differing skills associated with it, and thus no universally agreed on definition, has been cited as a limitation within the field (Hoffman, 2008; Osher et al., 2016). As a result, there are few SEL assessments with strong reliability and validity that examine both the knowledge and the ability to demonstrate SEL skills (Osher et al., 2016).

Further, each of the other variables examined are conceptualized as falling within the broad definition of SEL. According to CASEL, which is considered to be the most ubiquitous of the frameworks for SEL, competencies include self-awareness, social awareness, responsible decision making, self-management and relationship management. Self-efficacy is considered a skill which falls under self-awareness (Zins et al., 2004). The relationship between SEL and self-efficacy emerged as moderate to strong $(r=.61)$. Consequently, this was the strongest correlation amongst any of the variables. Also, perceived support from peers, teachers and parents could likely fall under an individual's relationship management skills. There were statistically significant, but small, correlations between the personal relationships subscale with peer support, teacher support and parent support. These correlational findings may lend evidence to SEL containing other constructs within it, which may have accounted for a more limited role.

Another important theme was that self-efficacy emerged as a variable that explained a significant amount of variance in academic achievement. This supports current literature that highlights the important role self-efficacy plays in education and achievement (Gaylon et al., 2012; Schunk et al., 2010; Affuso et al., 2016). Also noteworthy, it had the largest correlation with academic achievement of all examined variables. While this was not completely expected, there is a potential explanation for the findings. Self-efficacy encompasses a set of skills that allow students to gauge how successfully they can manage different experiences and situations, and is 
thought to be a task-specific compilation of skills. As many academic skills are task-specific, selfefficacy may help to explain how students perform. If a student believes that (s)he is able to be successful solving an algebraic equation, for example, (s)he may earn a better grade in Algebra I compared to a student who is less confident. In addition, self-efficacy is identified as a specific skill set that falls within SEL. Perhaps then, self-efficacy can be interpreted as a specific subcomponent of SEL that best explains the variance in the reported academic achievement. This would be something to examine in possible future studies. This may lend evidence to Payton et al. (2000), as it was suggested in CASEL's earlier work that self-efficacy could potentially serve as a foundational skill, one that is pertinent in developing further competencies within SEL.

The significance of SES also consistently explained variance of academic achievement, which suggested another major theme across analyses. As a reminder, it is important to remember that SES was coded as $1=$ Yes, student receives free and reduced lunch, and $0=$ No, does NOT receive free and reduced lunch. Thus, an inverse relationship between SES and achievement meant that lower SES (higher score on SES) was associated with poorer achievement. With this in mind, it was found to be statistically significant in every hierarchical regression. While not a substantial association, it was consistently suggesting an undeniable role in academic performance. This is not surprising, as prior research highlights that students that come from higher SES-backgrounds generally perform better in school (Van Ewijk \& Sleegers, 2010; Ransdell, 2012) and the importance of SES in education has been documented throughout the past several decades (Sirin, 2005; Harwell \& LeBeau, 2010).

Moreover, the predictive nature of microsystem variables was also investigated in this study. When examining academic achievement, contextual variables that focus on students' relationships with others played a significant role. When considering microsystem variables, 
parental involvement and teacher relationships significantly explained variance in academic achievement. These two variables contributed to the variance above and beyond demographics. In addition, when all variables were entered into a hierarchical regression, microsystem variables including parental involvement, teacher support, and peer support accounted for an additional amount of variance above and beyond everything else. This suggests that these variables play an important role in adolescent achievement when observing them in combination with other variables present in one's ecology. The current findings are consistent with previous literature signifying that support from teachers and peers, as well as parental involvement, is associated with higher academic performance in adolescents (Bissell-Harvan \& Loken, 2009; Tennant et al., 2015; Jeynes, 2012; Seginer, 2006).

Additionally, these findings indicate that achievement is not solely based on intrapersonal or microsystem variables. Rather, both were found to be equally important when examined separately, as they attributed to the same amount of variance. Even more importantly, when combined, it accounted for a larger amount of variance. Durlak et al. (2011) highlighted the position that learning is considered a collaborative process between various individuals, including teachers, peers, family members, and even one's self. This study supports the idea that collaboration of learning occurs between the individual and the various microsystems he or she interacts with. Overall, SEL, self-efficacy, parental involvement, and teacher relationships appear to best explain variation in academic achievement in this group of adolescent students. Findings revealed that when intrapersonal and microsystem factors were combined, more of the variance in academic achievement was accounted for. This lends more support to the notion that learning may be shaped and positively influenced by a myriad of ecological factors.

\section{Limitations and Future Directions}


There are several limitations that exist within the present study. To begin with, one of the limitations is that all responses were based on self-report data. Others' perceptions of the students' skills or behaviors were not taken into account, and it is important in research to collect measures from multiple perspectives, i.e., teachers and parents. Some students may have read questions and chosen to misreport their feelings, perhaps trying to answer how they think they should answer, versus sharing how they actually feel about certain topics. There were some similar questions amongst measures. Students may have answered one question differently than the other. For example, there were two questions that were posed about teachers caring about students. There may have been some overlap as a result in the final analyses of the measures. Moreover, some students may have circled all of the same responses for certain measures due to boredom or trying to quickly complete the survey, which could ultimately impact the accuracy of their reported feelings or attitudes. Lastly, some of the questions were left blank, either from students forgetting or choosing not to answer.

Also, at the high school level, students have multiple teachers, which may make it difficult to report feelings towards teachers in general, and in this study they were asked to report on teachers in aggregate and not individually. When asked to reflect on questions about their teachers, students may have instinctively thought of a teacher who they perceived to treat them rudely or failed to help when needed. This type of thinking could be the result of the negativity bias. Students may be more prone to remember the negative interactions or experiences with one teacher, and generalize it toward all teachers.

Another limitation to looking at the full developmental trend across the high school years is the smaller number of seniors in the sample, compared to freshman, sophomores, and juniors. The senior students accounted for only $14 \%$ of respondents. Although grade differences were 
accounted for with grade entered as a covariate in analyses, it may be beneficial for future research to include a more evenly distributed sample. In addition, because of the grade differences, it may be valuable for future studies to examine differences present in young adolescents versus older adolescents, as a way to further understand the ecological perspective of achievement over the high school years.

Next, the way in which SES was measured could also be considered a weakness. According to Harwell and LeBeau (2010), having free and reduced lunch as the SES proxy may be somewhat problematic because of potential deficiencies that can bias inferences, such as whether it accounts for a family's access to resources, or recognizing differing theoretical frameworks. However, it was the only option for the current study. This particular measure is identified as the SES measure in roughly $17 \%$ of education research articles (Sirin, 2005). It was necessary to account for information respondents would be able to quickly and accurately discern. This appeared to be a straightforward prompt in which students could readily answer. Perhaps looking forward, it may be helpful to have additional measures of SES that incorporate factors such as parent education level or household income.

Additionally, as alluded to earlier, the whole construct of SEL, while it seemed like a logical variable to include, may be problematic in terms of clarity of what construct is truly being measured. The construct of SEL is dependent on an array of skills, however, and there is no universally agreed upon framework (Hoffman, 2008; Osher et al., 2016). The SELS (Coryn et al., 2009) was selected because it specifically aligned with CASEL's core competencies. However, it has proven difficult to develop a construct of SEL that truly encompasses all of these skills. One that includes 20 questions may not fully encapsulate each of the competencies. Others in the field have noted the limited SEL assessments currently available, and have created a work group 
comprised of leading practitioners and educators to make advancements in social emotional competence assessments, as they have recognized the need for better tools (CASEL, 2016; Dirks, Treat, \& Weersing, 2007; Osher et al., 2016).

Looking towards the future, researchers must investigate the specific skills within SEL and determine which are the most important, or which need to be developed first in order to successfully build upon other skills. There is limited existing research that examines the intricacies or development of SEL (Osher et al., 2016). As a result, it is conceptualized as more of an umbrella-like set of skills, with some practitioners acknowledging some skills, and others acknowledging others. However, SEL could be considered a more reliable construct if there was more understanding of the theoretical framework in which these skills are thought to be developed. It would be beneficial for researchers to agree on universal language and common terms within a specific framework. Additionally, it may be useful to attempt to identify differences in skill acquisition for the different periods of development through childhood to adolescence. Perhaps researchers will want to re-examine SEL and academic achievement through an ecological perspective once they have created an agreed upon measure of the construct.

\section{Summary and Implications}

Despite the limitations of the current study, several of the findings make it a significant contribution to the existing literature on better understanding academic achievement through an ecological lens. With the ever increasing knowledge of the benefits of educating the whole child, fostering a diverse set of skills, including academic, as well as social-emotional skills shows promise in adolescents. This study has expanded the understanding of how multiple layers of one's ecology are simultaneously associated with academic performance. In examining which variables mattered most in terms of their connection with academic achievement, analyses revealed that 
demographic, intrapersonal, and microsystem variables significantly account for variance in the dependent measure, and when combined they have the largest impact. This provides educators with the knowledge of how to target the important factors within the home and school setting.

While SEL was revealed to have less predictive value than originally hypothesized, it still emerged as linked to academic achievement, which is similar to previously documented research (Durlak et al., 2011). With continued support of SEL, and inclusion of the construct at both the state and national education levels, the impact of SEL must continue to be examined and understood. As SEL skills are though to be malleable (Elias et al., 1997), targeting specific skills within the high school setting may be helpful in demonstrating a stronger link between SEL and academic achievement. One such SEL skill to focus on is self-efficacy. It is important for parents, educators, and students to understand the importance of student self-efficacy and its potential impact on achievement. Specifically selecting evidence-based programs that focus on fostering self-efficacy may be the most beneficial. Encouraging teachers to help students with problemsolving techniques, identification of emotions, and goal setting could all be ways in which SEL continues to be utilized in the classroom setting.

In addition, there are also implications for the results of the significant roles the microsystem level variables played. What makes the ecological context so unique is that there are ever changing interactions and experiences that shape one's development. This suggests that there are multiple opportunities in which individuals within the school environment can positively impact a student's achievement. Educators can engage in increased parent communication to encourage more involvement with school. While technology continues to advance, there are websites and online portals available in which parents can easily access grades and missing assignments for their children from their phones. These tools may possibly generate more 
involvement that could positively contribute to their children's academic success. In terms of fostering supportive teacher relationships, perhaps ancillary school support can promote staff to work on building relationships with more behaviorally challenging students, or set up teacherstudent mentoring to make sure each child in the school setting has an identified trusted adult. One possibility for fostering increased peer support would be to have teachers match up high-low pairings of students to allow student leaders to connect with students who may be having difficulty. All of these suggestions are the result of understanding the outcomes of this study, in combination with prior research, and identifying strategies that can be done to foster relationships between students and the individuals with whom they interact with in the microsystem of the school setting. 


\section{APPENDIX A: LETTER OF SUPPORT FROM MOTT HIGH SCHOOOL}

\section{MOTT HIGH SCHOOL}

1151 SCOTT LAKE RD. I WATERFORD, MI, 48328

Phone: 248.674.4134 Fax: 248.674.2825 Attendance: 248.674.4137

July 28, 2016

To whom it may concern:

This letter is to confirm that I have agreed to allow Meghan Fairless to collect data from students at Mott High School for her dissertation research examining the impact of social and emotional learning, along with ecological factors (such as school climate, parent relationship, teacher relationships, and peer relationships) on academic achievement. Meghan plans on running statistical analyses that look at factors as the best predictor of achievement using the data points gathered from our students at Mott High School.

I have been informed that students will have the opportunity to decline or discontinue participation at any time and I understand the methods will ensure student and family confidentiality.

Feel free to contact me with any questions at (313) 418-1025 or riggsi01 Qwwsdmi.ore.

Sincerely,

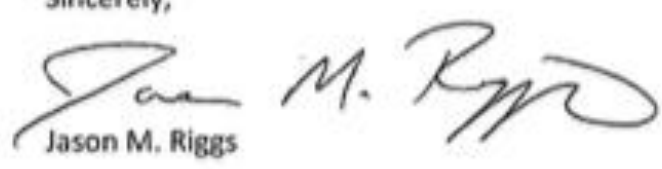

Waterford Mott High School Principal 


\section{APPENDIX B: HUMAN INVESTIGATION COMMITTEE APPROVAL}

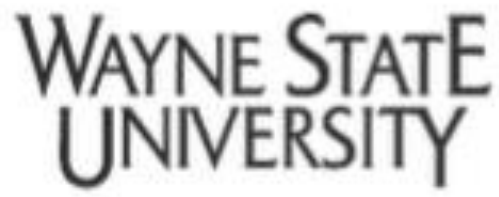

IRS Administration Orfice 87 East Canfield, Second Floor Detroit, Michlgan 48201 Whone: (313) 577.1628 FAx: (313) $993-712$

http://Rrb.wayne.edu

\section{NOTICE OF EXPEDITED AMENDMENT APPROVAL}

To: Moghan Fairless

Theoretical \& Behavior Foundations

C. 5425 Gullen mall

Fion

Doborah Elis or designee

Chairperson, Behavioral institutional Refiey Board (BS)

Date: Novernber 30,2016

RE:

IRB H: 08221683E

Protocol Tide: Social Emotional Leaming and Others Ecological Factors impact on Acadenic Achlevement

Funding Source:

Protocol t: $\quad 1606015152$

Expiration Date: $\quad$ September 29, 2019

Risk Level / Category: 45 CFR 46.404 - Research not involving greater than minimal riak

The above-refertenced protocol amendment, as liemized below, was reviewed by the Chairpersonidesignee of the Wayne State University hstitusional Review Board (B3) and is APPROVED effective immediately.

- Protocol - Data collection instrument changes include revised demographic measure and added questions.

- Information Sheet 8 . Assent Form - (1) Parent Supplemental information Letter with 'Decline to Participate' Option and (ii) Documentation of Adolescent Assent Form - Ages 13-17 modiled lo reflect the addison of the word "demographic" to describe the types of questions the students will have to complete.

- Data Collection Tools (2) - Recelpt of revised (1) Appendix. A: Surveylinstruments Measures and (in) Measures.

Notify the IRB of any changes to the funding status of the above-referenced protocol. 


\section{APPENDIX C: PARENT SUPPLEMENTAL INFORMATION LETTER Parent Supplemental Information Letter with "Decline to Participate" Option \\ Title of Study: Social-Emotional Learning and the Impact on \\ High School Academic Achievement \\ Researcher's Name: Meghan Fairless}

\section{Purpose:}

You are being asked to allow your child to be in a research study at their school that is being conducted by Ph.D. candidate Meghan Fairless in the department of Educational Psychology at Wayne State University to find out how social awareness and relationship skills, as well as confidence to succeed, perceived peer, parent, and teacher social supports, school climate, and parental involvement, are related to academic achievement. Your child has been selected, because he or she attends Waterford Mott High School, and is between 13 to 17 years of age. The estimated number of participated expected to enroll in this study is 400 students.

\section{Study Procedures:}

If you decide to allow your child to take part in the study, your child will be asked to participate in a brief study lasting no longer than thirty minutes. He or she will complete questionnaires addressing a number of topics, including social awareness and relationship skills, confidence to succeed, peer social support, parent social support, teacher social support, school climate, parental involvement, and academic achievement.

- Your child has the option of not answering some of the questions in the study, may decline participation, or withdraw from the study entirely, even after deciding to participate.

- Your child will be in the study for one 30-minute survey, which will take place in his or her Academic Center class for one day.

- Copies of the survey are held by the primary investigator (Meghan Fairless) and the supervising professor and may be reviewed by the parents upon request.

\section{Benefits:}

As a participant in this research study, there may be no direct benefit for your child; however, information from this study may benefit other people now, or in the future.

\section{Risks:}

There are no known risks at this time to participate in the study.

\section{Costs:}

There are no costs to you or your child to participate in this study.

\section{Compensation:}

For taking part in this research study, your child will receive a piece of candy of his or her choosing.

\section{Confidentiality:}

All information collected about your child during the course of this study will be kept confidential to the extent permitted by law. All information collected about your child during the course of this study will be kept without any identifiers. Thus, the data are anonymous. There is no way to trace a survey or response back to a particular student. 


\section{Voluntary Participation/Withdrawal:}

Your child's participation in this study is voluntary. He/she may withdraw at any time. You are free to withdraw your child at any time. Your decision about enrolling your child in the study will not change any present or future relationships with Wayne State University or its affiliates, your child's school, your child's teacher, your child's grades or other services you or your child are entitled to receive.

\section{Questions:}

If you have any questions about this study now or in the future, you may contact Meghan Fairless at the following phone number: (248) 515 - 9447. If you have questions or concerns about your rights as a research participant, the Chair of the Institutional Review Board can be contacted at (313) 577-1628. If you are unable to contact the research staff, or if you want to talk to someone other than the research staff, you may also call (313) 577-1628 to ask questions or voice concerns or complaints. You may email me at Meghan.fairless@wayne.edu if you would like to request copies of the instruments.

\section{Participation:}

If you do not contact the principal investigator (PI) within a 2-week period, to state that you do not give permission for your child to be in research, your child will be enrolled into the research. You may contact the PI by calling the school at (248) 674 - 4134, emailing Meghan.Fairless@wayne.edu, or by signing and submitting the tear off sheet at the bottom of the page to Mott High School, located at 1151 Scott Lake Road, Waterford, Michigan.

\section{Optional Tear Off}

If you do not wish to have your child participate in the study, you may fill out the tear off form below and return it to the school.

I do not allow my child study.

(Student Name) to participate in this research

Printed Name of Parent 


\section{APPENDIX D: ADMINISTRATION SCRIPT Administration Script}

Good morning/afternoon class,

My name is Meghan Fairless and I am a doctoral student at Wayne State University.

Today you will have the opportunity to participate in a survey about how different factors such as social-emotional learning, self-efficacy, social support and school climate are related to academic achievement. The survey will ask a number of questions, and should only take about 30 minutes.

A form was mailed to your home that explained this to your parents also. Your parents have had the option to not have you participate. You do not have to complete the surveys if you do not want to. You can stop the survey at any time. Your completion of the survey will not affect the way are treated by any staff member or myself.

Please be sure to read both pages of the information sheet we give you. If you choose to be in the study, please pick up a survey from this envelope (marked "blank surveys"). Bring the survey back to your desk and fill it out. Please keep your answers covered with a piece of paper as you go, so no one can see your answers. Keep your eyes on your own survey. Please check to make sure you have answered all questions on the survey. Please remember this is not a test and it will not be graded. It does not have an impact on your grades or school work whatsoever. It is important that you are very honest. Please do not put your name on any of the surveys. Each packet is uniquely coded with a number that identifies the data only, not you as a person. The surveys are completely anonymous, so no one will ever know what answers you give.

Please raise your hand if you need help at any time. When you are done with the survey, bring it back up to me, and place it in this envelope (marked "finished surveys"). You can then take a piece of candy, even if you did not complete the entire survey. If you are not participating, you can complete course work as regularly scheduled.

It is very important that you do not discuss the survey or your answers with other students or staff. If you have any questions, please tell an adult at school.

Thank you very much. 


\title{
APPENDIX E: DOCUMENTATION OF ADOLESCENT ASSENT FORM Documentation of Adolescent Assent Form
}

\author{
(Ages 13-17)
}

Title: Social-Emotional Learning and the Impact on High School Academic Achievement
Study Investigator: Meghan Fairless

\section{Why am I here?}

This is a research study. Only people who choose to take part are included in research studies. You are being asked to take part in this study because you are a student attending Waterford Mott High School, and are between the ages of 13 years to 17 years. The estimated number of participated expected to enroll in this study is 400 students. Please take time to make your decision. Be sure to ask questions about anything you do not understand.

\section{Why are they doing this study?}

This study is being done to find out what factors predict students' academic achievement. The factors will help to understand the impact of social awareness and relationship skills, confidence to succeed, perceived social support from peers, teachers, and parents, school climate, and parental involvement impact achievement.

\section{What will happen to me?}

You will be provided the opportunity to complete a short survey that will ask questions about the how your social awareness and relationship skills, confidence to succeed, perceived social support from peers, teachers and parents, school climate, and parental involvement on academic achievement.

\section{How long will I be in the study?}

You will be in the study for just this one-time survey, which is expected to last no longer than 30 minutes.

\section{Will the study help me?}

You may not benefit from being in the study; however, information from this study may help others now or in the future.

\section{Will anything bad happen to me?}

There are no known risks at this time to participating in the this study.

\section{Will I get paid to be in the study?}

For taking part in this research study, you will receive a piece of candy of your choosing.

\section{Do my parents or guardians know about this? (If applicable)}

This study information has been given to your parents or guardian, and they were given the opportunity to decline your participation. You can talk this over with them before you decide whether you wish to participate. However, nobody will ever be allowed to see your answers.

\section{What about confidentiality?}

This study is completely anonymous. You will not write your name on the survey, so none of the 
information you provide can be linked back to you. We will keep your records private unless we are required by law to share any information. The law only says that we have to tell someone if you might hurt yourself or someone else.

What if I have any questions?

For questions about the study please call Meghan Fairless at (248) 515 - 9447. If you have questions or concerns about your rights as a research participant, the Chair of the Institutional Review Board can be contacted at (313) 577 - 1628.

\section{Do I have to be in the study?}

You do not have to participate in this study if you do not want to. You can stop participation in the study at any time. Please discuss your decision with your parents and researcher. No one will be angry if you decide to stop being in the study. 


\section{APPENDIX F: SURVEY INSTRUMENTS \\ Demographics}

1. What grade are you in?

$$
9^{\text {th }} \text { Grade } \quad 10^{\text {th }} \text { Grade } \quad 11^{\text {th }} \text { Grade } \quad 12^{\text {th }} \text { grade }
$$

2. How old are you?

13 years old $\quad 14$ years old $\quad 15$ years old $\quad 16$ years old 17 years old

3. What is your gender?

Male Female

4. Do you receive free or reduced lunch?

Yes No

5. With which ethnic/racial category do you most identify? (Check all that apply)

$\begin{array}{lll}\text { African American/Black } & \text { Hispanic } & \text { Asian/Pacific Islander } \\ \text { Caucasian } & \text { Middle Eastern } & \text { Other }\end{array}$

6. What are the current grades in your core classes? (Language Arts, Math, Science, Social Studies)

Circle N/A if you are not enrolled in the class.

Language Arts:
A A
$\mathrm{B}+\quad \mathrm{B}$
B- $\mathrm{C}+\mathrm{C} \quad \mathrm{C}-$
D+ D
D- E
N/A

Math:
$\mathrm{A} \quad \mathrm{A}-\mathrm{B}+\mathrm{B}$
B- $\mathrm{C}+\mathrm{C}$
C-
D+ D D- E
N/A

Science (Biology, Chemistry, Physics, Environmental Science, Astronomy)
A
A- B+ B
B- $\mathrm{C}+$
C C- D+ D
D- $E$
N/A

Social Studies (US History, World Studies, American Civics):
A
A- $\mathrm{B}+\mathrm{B}$
B- $\mathrm{C}+\mathrm{C}$
C- $\quad$ D+ $\quad$ D
D- $\quad \mathrm{E}$
N/A

7. What grades do you typically receive?

Mostly As

Mostly Bs and Cs

Mostly Ds
Mostly As and Bs

Mostly Cs

Mostly Ds and E's
Mostly Bs

Mostly Cs and Ds

Mostly Es 
Social-Emotional Learning Scale (SELS) (Coryn, 2009)

\begin{tabular}{|c|c|c|c|c|c|}
\hline & $\begin{array}{l}\text { Strongly } \\
\text { Disagree } \\
(1) \\
\end{array}$ & $\begin{array}{c}\text { Disagree } \\
\text { (2) }\end{array}$ & $\begin{array}{c}\text { Neutral } \\
\text { (3) }\end{array}$ & $\begin{array}{l}\text { Agree } \\
\text { (4) }\end{array}$ & $\begin{array}{l}\text { Strongly } \\
\text { Agree (5) }\end{array}$ \\
\hline $\begin{array}{l}\text { 1. I understand situations that cause me to } \\
\text { feel happy, sad, angry or frustrated }\end{array}$ & 1 & 2 & 3 & 4 & 5 \\
\hline $\begin{array}{l}\text { 2. I understand the feelings expressed by } \\
\text { others }\end{array}$ & 1 & 2 & 3 & 4 & 5 \\
\hline $\begin{array}{l}\text { 3. I understand that I am responsible for my } \\
\text { own actions }\end{array}$ & 1 & 2 & 3 & 4 & 5 \\
\hline $\begin{array}{l}\text { 4. I can express my emotions without } \\
\text { getting mad, excited, or yelling }\end{array}$ & 1 & 2 & 3 & 4 & 5 \\
\hline 5. I understand the need for rules at school & 1 & 2 & 3 & 4 & 5 \\
\hline $\begin{array}{l}\text { 6. I identify differences among cultural } \\
\text { groups }\end{array}$ & 1 & 2 & 3 & 4 & 5 \\
\hline $\begin{array}{l}\text { 7. I figure out ahead of time how certain } \\
\text { situations may get me into trouble }\end{array}$ & 1 & 2 & 3 & 4 & 5 \\
\hline $\begin{array}{l}\text { 8. I work positively in groups with people } \\
\text { who are different from me }\end{array}$ & 1 & 2 & 3 & 4 & 5 \\
\hline $\begin{array}{l}\text { 9. I am able to talk to my parents and } \\
\text { teachers about interests I have }\end{array}$ & 1 & 2 & 3 & 4 & 5 \\
\hline $\begin{array}{l}\text { 10. I understand how my family, school and } \\
\text { others in the community can support my } \\
\text { success in school }\end{array}$ & 1 & 2 & 3 & 4 & 5 \\
\hline $\begin{array}{l}\text { 11. I know different ways to make and keep } \\
\text { friends }\end{array}$ & 1 & 2 & 3 & 4 & 5 \\
\hline $\begin{array}{l}\text { 12. I am able to say no to people or } \\
\text { situations that may get me into trouble }\end{array}$ & 1 & 2 & 3 & 4 & 5 \\
\hline $\begin{array}{l}\text { 13. I figure out different solutions to school } \\
\text { problems }\end{array}$ & 1 & 2 & 3 & 4 & 5 \\
\hline $\begin{array}{l}\text { 14. I can explain what I need to do to reach a } \\
\text { goal }\end{array}$ & 1 & 2 & 3 & 4 & 5 \\
\hline $\begin{array}{l}\text { 15. I figure out different ways to work } \\
\text { effectively in groups }\end{array}$ & 1 & 2 & 3 & 4 & 5 \\
\hline $\begin{array}{l}\text { 16. I keep track of my progress towards a } \\
\text { goal }\end{array}$ & 1 & 2 & 3 & 4 & 5 \\
\hline $\begin{array}{l}\text { 17. I understand what causes problems } \\
\text { among my friends }\end{array}$ & 1 & 2 & 3 & 4 & 5 \\
\hline $\begin{array}{l}\text { 18. I figure out different solutions to } \\
\text { personal problems }\end{array}$ & 1 & 2 & 3 & 4 & 5 \\
\hline $\begin{array}{l}\text { 19. I can help solve problems among friends } \\
\text { in a positive way }\end{array}$ & 1 & 2 & 3 & 4 & 5 \\
\hline 20. I help out at my school & 1 & 2 & 3 & 4 & 5 \\
\hline
\end{tabular}


The Self-Efficacy Questionnaire for Children (SEQ-C) (Muris, 2001)

\begin{tabular}{|c|c|c|c|c|c|}
\hline & $\begin{array}{l}\text { Not At } \\
\text { All (1) }\end{array}$ & (2) & (3) & (4) & $\begin{array}{c}\text { Very } \\
\text { Well (5) }\end{array}$ \\
\hline $\begin{array}{l}\text { 1. How well can you get teachers to help you when you } \\
\text { get stuck on schoolwork? }\end{array}$ & 1 & 2 & 3 & 4 & 5 \\
\hline $\begin{array}{l}\text { 2. How well can you express your opinions when other } \\
\text { classmates disagree with you? }\end{array}$ & 1 & 2 & 3 & 4 & 5 \\
\hline $\begin{array}{l}\text { 3. How well do you succeed in cheering yourself up } \\
\text { when an unpleasant event has happened? }\end{array}$ & 1 & 2 & 3 & 4 & 5 \\
\hline $\begin{array}{l}\text { 4. How well can you study when there are other } \\
\text { interesting things to do? }\end{array}$ & 1 & 2 & 3 & 4 & 5 \\
\hline $\begin{array}{l}\text { 5. How well do you succeed in becoming calm again } \\
\text { when you are very scared? }\end{array}$ & 1 & 2 & 3 & 4 & 5 \\
\hline $\begin{array}{l}\text { 6. How well can you become friends with other } \\
\text { children? }\end{array}$ & 1 & 2 & 3 & 4 & 5 \\
\hline 7. How well can you study for a test? & 1 & 2 & 3 & 4 & 5 \\
\hline $\begin{array}{l}\text { 8. How well can you have a chat with an unfamiliar } \\
\text { person? }\end{array}$ & 1 & 2 & 3 & 4 & 5 \\
\hline 9. How well can you prevent to become nervous? & 1 & 2 & 3 & 4 & 5 \\
\hline $\begin{array}{l}\text { 10. How well do you succeed in finishing your } \\
\text { homework every day? }\end{array}$ & 1 & 2 & 3 & 4 & 5 \\
\hline $\begin{array}{l}\text { 11. How well can you work in harmony with your } \\
\text { classmates? }\end{array}$ & 1 & 2 & 3 & 4 & 5 \\
\hline 12. How well can you control your feelings? & 1 & 2 & 3 & 4 & 5 \\
\hline 13. How well can you pay attention during every class? & 1 & 2 & 3 & 4 & 5 \\
\hline $\begin{array}{l}\text { 14. How well can you tell other children that they are } \\
\text { doing something that you don't like? }\end{array}$ & 1 & 2 & 3 & 4 & 5 \\
\hline $\begin{array}{l}\text { 15. How well can you give yourself a pep-talk when you } \\
\text { feel low? }\end{array}$ & 1 & 2 & 3 & 4 & 5 \\
\hline 16. How well do you succeed in passing all subjects? & 1 & 2 & 3 & 4 & 5 \\
\hline $\begin{array}{l}\text { 17. How well can you tell a funny event to a group of } \\
\text { children? }\end{array}$ & 1 & 2 & 3 & 4 & 5 \\
\hline 18. How well can you tell a friend you don't feel well? & 1 & 2 & 3 & 4 & 5 \\
\hline $\begin{array}{l}\text { 19. How well do you succeed in satisfying your parents } \\
\text { with your schoolwork? }\end{array}$ & 1 & 2 & 3 & 4 & 5 \\
\hline $\begin{array}{l}\text { 20. How well do you succeed in staying friends with } \\
\text { other children? }\end{array}$ & 1 & 2 & 3 & 4 & 5 \\
\hline $\begin{array}{l}\text { 21. How well do you succeed in suppressing unpleasant } \\
\text { thoughts? }\end{array}$ & 1 & 2 & 3 & 4 & 5 \\
\hline 22. How well do you succeed in passing a test? & 1 & 2 & 3 & 4 & 5 \\
\hline $\begin{array}{l}\text { 23. How well do you succeed in preventing quarrels with } \\
\text { others? }\end{array}$ & 1 & 2 & 3 & 4 & 5 \\
\hline $\begin{array}{l}\text { 24. How well do you succeed in not worrying about things } \\
\text { that might happen? }\end{array}$ & 1 & 2 & 3 & 4 & 5 \\
\hline
\end{tabular}




\begin{tabular}{|c|c|c|c|c|}
\hline $\begin{array}{l}\text { School Climate Scale } \\
\text { Please read each statement and mark the response } \\
\text { that best shows how much you agree. }\end{array}$ & $\begin{array}{c}\text { Disagree A } \\
\text { LOT (1) }\end{array}$ & $\begin{array}{c}\text { Disagree } \\
\text { (2) }\end{array}$ & $\begin{array}{c}\text { Agree } \\
\text { (3) }\end{array}$ & $\begin{array}{c}\text { Agree } \\
\text { A LOT (4) }\end{array}$ \\
\hline \multicolumn{5}{|l|}{ IN THIS SCHOOL... } \\
\hline 1. Most students turn in their homework on time. & 1 & 2 & 3 & 4 \\
\hline 2. Teachers treat students of all races with respect. & 1 & 2 & 3 & 4 \\
\hline 3. The school rules are fair. & 1 & 2 & 3 & 4 \\
\hline 4. Students are safe in the hallways. & 1 & 2 & 3 & 4 \\
\hline 5. Rules are made clear to students. & 1 & 2 & 3 & 4 \\
\hline 6. Most students try their best. & 1 & 2 & 3 & 4 \\
\hline 7. Teachers care about their students. & 1 & 2 & 3 & 4 \\
\hline 8. The consequences of breaking rules are fair. & 1 & 2 & 3 & 4 \\
\hline 9. Students threaten and bully others. & 1 & 2 & 3 & 4 \\
\hline 10. Students know how they are expected to act. & 1 & 2 & 3 & 4 \\
\hline 11. Students are friendly with each other. & 1 & 2 & 3 & 4 \\
\hline 12. Adults care about students of all races. & 1 & 2 & 3 & 4 \\
\hline 13. Students feel safe. & 1 & 2 & 3 & 4 \\
\hline 14. Students worry about others bullying them. & 1 & 2 & 3 & 4 \\
\hline 15. Students know what the rules are. & 1 & 2 & 3 & 4 \\
\hline 16. Students care about each other. & 1 & 2 & 3 & 4 \\
\hline 17. Teachers listen to students when they have & 1 & 2 & 3 & 4 \\
\hline 18. The school's Code of Conduct is fair. & 1 & 2 & 3 & 4 \\
\hline 19. Students know they are safe. & 1 & 2 & 3 & 4 \\
\hline 20. It is clear how students are expected to act. & 1 & 2 & 3 & 4 \\
\hline 21.Students respect others who are different & 1 & 2 & 3 & 4 \\
\hline 22. Adults who work here care about the students. & 1 & 2 & 3 & 4 \\
\hline 23. Most students follow the rules. & 1 & 2 & 3 & 4 \\
\hline 24. Bullying is a problem. & 1 & 2 & 3 & 4 \\
\hline 25. Most students like this school. & 1 & 2 & 3 & 4 \\
\hline 26. Students of different races get along. & 1 & 2 & 3 & 4 \\
\hline 27. Teachers expect the best from all races. & 1 & 2 & 3 & 4 \\
\hline 28. Classroom rules are fair. & 1 & 2 & 3 & 4 \\
\hline 29. Most students work hard to get good grades. & 1 & 2 & 3 & 4 \\
\hline 30. Students treat each other with respect. & 1 & 2 & 3 & 4 \\
\hline 31. Students get along with each other. & 1 & 2 & 3 & 4 \\
\hline 32. Teachers like their students. & 1 & 2 & 3 & 4 \\
\hline 33. Students bully one another. & 1 & 2 & 3 & 4 \\
\hline 34. Most students feel happy. & 1 & 2 & 3 & 4 \\
\hline
\end{tabular}




\begin{tabular}{|c|c|c|c|c|c|}
\hline \multicolumn{6}{|c|}{ Commitment to Achievement Measure (Paulson, 1994) } \\
\hline $\begin{array}{l}\text { Indicate the number which best describes your } \\
\text { parent/guardian from } 1 \text { to } 5 \text { for each item }\end{array}$ & $\begin{array}{l}\text { Very } \\
\text { Unlike } \\
\text { (1) }\end{array}$ & $\begin{array}{l}\text { More } \\
\text { Unlike } \\
\text { than } \\
\text { Like (2) }\end{array}$ & $\begin{array}{l}\text { Neither Like } \\
\text { nor Unlike } \\
\text { (3) }\end{array}$ & $\begin{array}{l}\text { More Like } \\
\text { than Unlike } \\
\text { (4) }\end{array}$ & $\begin{array}{c}\text { Very } \\
\text { Like (5) }\end{array}$ \\
\hline $\begin{array}{l}\text { 1. My parent/guardian tries to get me to do my } \\
\text { best on everything I do }\end{array}$ & 1 & 2 & 3 & 4 & 5 \\
\hline $\begin{array}{l}\text { 2. My parent/guardian thinks that education is a } \\
\text { very important part of adolescence }\end{array}$ & 1 & 2 & 3 & 4 & 5 \\
\hline $\begin{array}{l}\text { 3. My parent/guardian usually goes to parent- } \\
\text { teacher conferences }\end{array}$ & 1 & 2 & 3 & 4 & 5 \\
\hline $\begin{array}{l}\text { 4. My parent/guardian usually sets high standards } \\
\text { for me to meet }\end{array}$ & 1 & 2 & 3 & 4 & 5 \\
\hline $\begin{array}{l}\text { 5. My parent/guardian seldom looks at my tests } \\
\text { and papers from school }\end{array}$ & 1 & 2 & 3 & 4 & 5 \\
\hline $\begin{array}{l}\text { 6. It does not really matter to my parent/guardian } \\
\text { what grades I get }\end{array}$ & 1 & 2 & 3 & 4 & 5 \\
\hline $\begin{array}{l}\text { 7. My parent/guardian is not involved in school } \\
\text { programs for parents }\end{array}$ & 1 & 2 & 3 & 4 & 5 \\
\hline $\begin{array}{l}\text { 8. My parent/guardian sometimes does volunteer } \\
\text { work at my school }\end{array}$ & 1 & 2 & 3 & 4 & 5 \\
\hline $\begin{array}{l}\text { 9. My parent/guardian thinks homework is a very } \\
\text { important part of school }\end{array}$ & 1 & 2 & 3 & 4 & 5 \\
\hline $\begin{array}{l}\text { 10. When I get poor grades, my parent/guardian } \\
\text { encourages me to try harder }\end{array}$ & 1 & 2 & 3 & 4 & 5 \\
\hline $\begin{array}{l}\text { 11. My parent/guardian usually does not go to } \\
\text { school functions }\end{array}$ & 1 & 2 & 3 & 4 & 5 \\
\hline $\begin{array}{l}\text { 12. My parent/guardian makes sure that I have } \\
\text { done my homework }\end{array}$ & 1 & 2 & 3 & 4 & 5 \\
\hline $\begin{array}{l}\text { 13. My parent/guardian usually knows what grades } \\
\text { I get }\end{array}$ & 1 & 2 & 3 & 4 & 5 \\
\hline $\begin{array}{l}\text { 14. My parent/guardian thinks I should go to } \\
\text { college }\end{array}$ & 1 & 2 & 3 & 4 & 5 \\
\hline $\begin{array}{l}\text { 15. Hard work is very important to my } \\
\text { parent/guardian }\end{array}$ & 1 & 2 & 3 & 4 & 5 \\
\hline $\begin{array}{l}\text { 16. My parent/guardian does not think that (s)he } \\
\text { help me with my homework }\end{array}$ & 1 & 2 & 3 & 4 & 5 \\
\hline $\begin{array}{l}\text { 17. My parent/guardian has high aspirations for my } \\
\text { future }\end{array}$ & 1 & 2 & 3 & 4 & 5 \\
\hline $\begin{array}{l}\text { 18. When I get poor grades, my parent/guardian } \\
\text { offers help }\end{array}$ & 1 & 2 & 3 & 4 & 5 \\
\hline $\begin{array}{l}\text { 19. When I ask for help with homework, my } \\
\text { parent/guardian usually gives it to me }\end{array}$ & 1 & 2 & 3 & 4 & 5 \\
\hline $\begin{array}{l}\text { 20. My parent/guardian thinks that getting ahead in } \\
\text { life is very important }\end{array}$ & 1 & 2 & 3 & 4 & 5 \\
\hline $\begin{array}{l}\text { 21. My parent/guardian does not think I should be } \\
\text { concerned about what kind of career I may } \\
\text { have }\end{array}$ & 1 & 2 & 3 & 4 & 5 \\
\hline $\begin{array}{l}\text { 22. My parent/guardian usually goes to activities in } \\
\text { which I am involved in at school }\end{array}$ & 1 & 2 & 3 & 4 & 5 \\
\hline
\end{tabular}


How Often?

My Parent(s)...

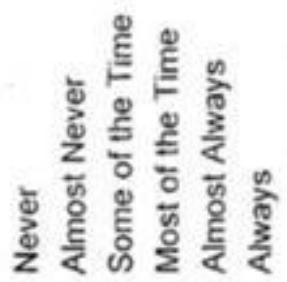

My Parent(s)...

1....show they are proud of me. 123456

2. ...understand me. $\quad 1223456$

3. ... listen to me when I need to talk. $\quad \begin{array}{llllll}1 & 2 & 3 & 4 & 5 & 6\end{array}$

4. ...make suggestions when I don't know what to do. $\quad \begin{array}{llllll}1 & 2 & 3 & 4 & 5 & 6\end{array}$

5. ... give me good advice. $\quad \begin{array}{llllll}1 & 2 & 3 & 4 & 5 & 6\end{array}$

6. ...help me solve problems by giving me information. $\begin{array}{lllllll}1 & 2 & 3 & 4 & 5 & 6\end{array}$

7...tell me I did a good job when I do something well. $\quad \begin{array}{llllll}1 & 2 & 3 & 4 & 5 & 6\end{array}$

\begin{tabular}{lllllll}
\hline $8 . . . . n$ nicely tell me when I make mistakes. & 1 & 2 & 3 & 4 & 5 & 6
\end{tabular}

9.... reward me when l've done something well. $\quad 123456$

\begin{tabular}{lllllll}
\hline $10 . . . h$ help me practice my activities. & 1 & 2 & 3 & 4 & 5 & 6
\end{tabular}

\begin{tabular}{lllllll}
\hline $11 . .$. take time to help me decide things. & 1 & 2 & 3 & 4 & 5 & 6 \\
\hline $12 . .$. get me many of the things I need. & 1 & 2 & 3 & 4 & 5 & 6
\end{tabular}

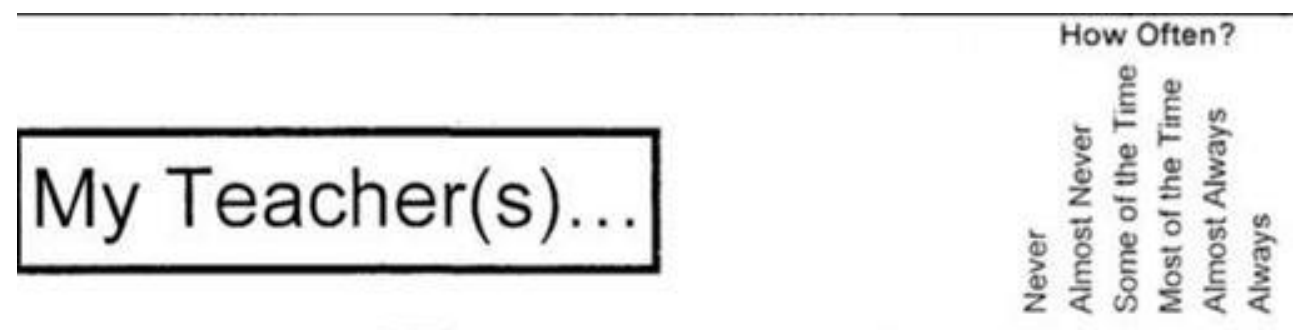

\begin{tabular}{|c|c|c|c|c|c|c|}
\hline My Teacher(s)... & & & & & & \\
\hline 13....cares about me. & 1 & 2 & 3 & 4 & 5 & 6 \\
\hline 14....treats me fairly. & 1 & 2 & 3 & 4 & 5 & 6 \\
\hline 15.... makes it okay to ask questions. & 1 & 2 & 3 & 4 & 5 & 6 \\
\hline 16. ...explains things that I don't understand. & 1 & 2 & 3 & 4 & 5 & 6 \\
\hline 17. ... shows me how to do things. & 1 & 2 & 3 & 4 & 5 & 6 \\
\hline $\begin{array}{l}\text { 18....helps me solve problems by giving me } \\
\text { information. }\end{array}$ & 1 & 2 & 3 & & 5 & 6 \\
\hline $\begin{array}{l}\text { 19. ... tells me I did a good job when I've done } \\
\text { something well. }\end{array}$ & 1 & 2 & 3 & & 5 & 6 \\
\hline 20. ... nicely telis me when I make mistakes. & 1 & 2 & 3 & 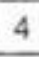 & 5 & 6 \\
\hline 21....tells me how well I do on tasks. & 1 & 2 & 3 & 4 & 5 & 6 \\
\hline 22. ... makes sure I have what I need for school. & 1 & 2 & 3 & 4 & 5 & 6 \\
\hline 23....takes time to help me learn to do something well. & 1 & 2 & 3 & 4 & 5 & 6 \\
\hline 24. .... spends time with me when I need help. & 1 & 2 & 3 & & 5 & 6 \\
\hline
\end{tabular}




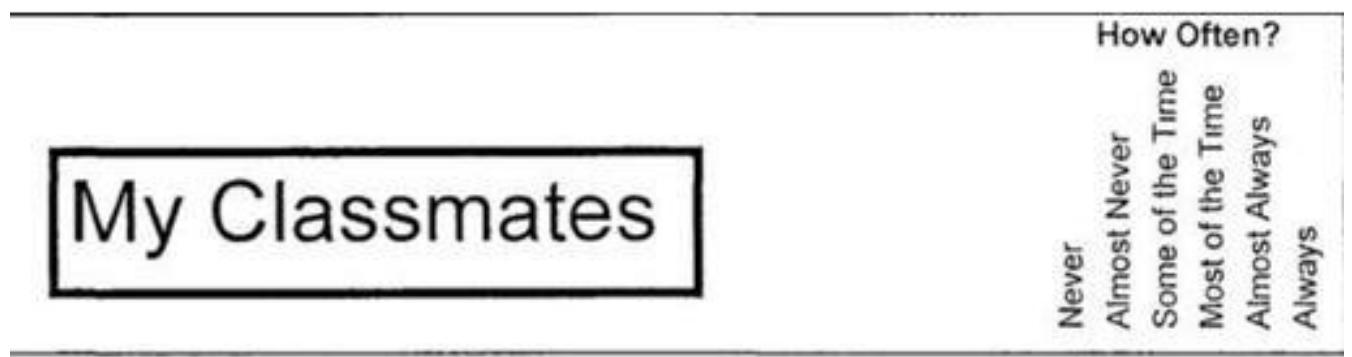

My Classmates...

25. ...treat me nicely. $\quad \begin{array}{llllll}2 & 2 & 3 & 4 & 5 & 6\end{array}$

26. ... like most of my ideas and opinions. $\quad \begin{array}{llllll}1 & 2 & 3 & 4 & 5 & 6\end{array}$

27.... pay attention to me. $12 \begin{array}{lllll}3 & 4 & 5 & 6\end{array}$

28. . give me ideas when I don't know what to do $\quad \begin{array}{llllll}1 & 2 & 3 & 4 & 5 & 6\end{array}$

29. ...give me information so I can learn new things. $\quad \begin{array}{llllll}1 & 2 & 3 & 4 & 5 & 6\end{array}$

30. ... give me good advice. $1 \begin{array}{llllll}1 & 2 & 3 & 4 & 5 & 6\end{array}$

31....tell me I did a good job when l've done something $1 \begin{array}{llllll}1 & 2 & 3 & 4 & 5 & 6\end{array}$ well

32. ...nicely tell me when I make mistakes. $\quad \begin{array}{llllll}1 & 2 & 3 & 4 & 5 & 6\end{array}$

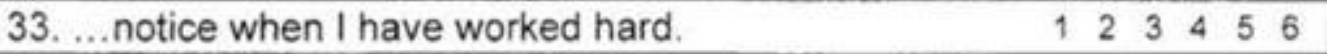

34. ... ask me to join activities $\quad \begin{array}{llllll}1 & 2 & 3 & 4 & 5 & 6\end{array}$

35.... spend time doing things with me. $\quad 123456$

36. ...help me with projects in class. 1234456 


\section{REFERENCES}

Adelman, H. S., \& Taylor, L. (2006). Mental health in schools and public health. Public Health Reports, 121(3), 294-298.

Affuso, G., Bacchini, D., \& Miranda, M. C. (2016). The contribution of school-related parental monitoring, self-determination, and self-efficacy to academic achievement. The Journal of Educational Research, 1-10.

Anderman, L. H. (1999). Expanding the discussion of social perceptions and academic outcomes: Mechanisms and contextual influences. In T. Urdan (Ed.), Advances in Motivation and Achievement, Vol. 11: The Role of Contextual Influences on Motivation. New York: JAI.

Arslan, S. (2015). Social Emotional learning and educational stress: A predictive model. Educational Research and Reviews, 10(2), 184-190.

Baker, J. A. (1999). Teacher-student interaction in urban at-risk classrooms: Differential behavior, relationship quality, and student satisfaction with school. The Elementary School Journal, 5770.

Bandura, A. (1995). Self-efficacy in changing societies. Cambridge university press.

Bandura, A. (1997). Self-efficacy: The exercise of control. New York, NY: Freeman.

Bandura, A., Barbaranelli, C., Caprara, G. V., \& Pastorelli, C. (1996). Multifaceted impact of selfefficacy beliefs on academic functioning. Child development, 1206-1222.

Bear, G. G., Gaskins, C., Blank, J., \& Chen, F. F. (2011). Delaware School Climate SurveyStudent: Its factor structure, concurrent validity, and reliability. Journal of School Psychology, 49(2), 157-174. 
Bear, G. G., Yang, C., Pell, M., \& Gaskins, C. (2014). Validation of a brief measure of teachers' perceptions of school climate: Relations to student achievement and suspensions. Learning Environments Research, 17(3), 339-354.

Benson, P. L. (2006). All kids are our kids: What communities must do to raise caring and responsible children and adolescents ( $2^{\text {nd }}$ ed.). San Francisco: Jossey-Bass.

Bissell-Havran, J. M., \& Loken, E. (2009). The role of friends in early adolescents' academic selfcompetence and intrinsic value for math and English. Journal of Youth and Adolescence, 38(1), 41-50.

Blum, R. W., Libbey, H. P., Bishop, J. H., \& Bishop, M. (2004). School connectednessstrengthening health and education outcomes for teenagers. Journal of School Health, 74(7), 231-235.

Bogenschneider, K. (1996). An ecological risk/protective theory for building prevention programs, policies, and community capacity to support youth. Family relations, 45(2), 127 - 138.

Bong, M., \& Skaalvik, E. M. (2003). Academic self-concept and self-efficacy: How different are they really?. Educational psychology review, 15(1), 1-40.

Bouchey, H. A., \& Harter, S. (2005). Reflected Appraisals, Academic Self-Perceptions, and Math/Science Performance During Early Adolescence. Journal of Educational Psychology, $97(4), 673$.

Breslau, J., Lane, M., Sampson, N., \& Kessler, R. C. (2008). Mental disorders and subsequent educational attainment in a US national sample. Journal of psychiatric research, 42(9), 708716.

Bronfenbrenner, U. (1979). The ecology of human development: Experiments by nature and design. Cambridge MA: Harvard University Press. 
Bronfenbrenner, U., \& Morris, P. A. (1998). The ecology of developmental processes in: Damon, W., Lerner, R. M. (Eds.), Theoretical models of human development, Handbook of child psychology (5 ${ }^{\text {th }}$ ed.), Vol 1., Wiley, New York: NY, pp. $993-1023$.

Brown, S. D., Tramayne, S., Hoxha, D., Telander, K., Fan, X., \& Lent, R. W. (2008). Social cognitive predictors of college students' academic performance and persistence: A metaanalytic path analysis. Journal of Vocational Behavior, 72(3), 298-308.

Bryan, J., Moore-Thomas, C., Gaenzle, S., Kim, J., Lin, C. H., \& Na, G. (2012). The effects of school bonding on high school seniors' academic achievement. Journal of Counseling \& Development, 90(4), 467-480.

Burns, B. J., Costello, E. J., Angold, A., Tweed, D., Stangl, D., Farmer, E. M., \& Erkanli, A. (1995). Children's mental health service use across service sectors. Health affairs, 14(3), 147159.

Carroll, A., Houghton, S., Wood, R., Unsworth, K., Hattie, J., Gordon, L., \& Bower, J. (2009). Self-efficacy and academic achievement in Australian high school students: The mediating effects of academic aspirations and delinquency. Journal of Adolescence, 32(4), 797-817.

Catalano, R. F., Berglund, M. L., Ryan, J. A., Lonczak, H. S., \& Hawkins, J. D. (2004). Positive youth development in the United States: Research findings on evaluations of positive youth development programs. The annals of the American academy of political and social science, 591(1), 98-124.

Catsambis, S. (2001). Expanding knowledge of parental involvement in children's secondary education: Connections with high school seniors' academic success. Social Psychology of Education, 5(2), 149-177. 
Chemers, M. M., Hu, L. T., \& Garcia, B. F. (2001). Academic self-efficacy and first year college student performance and adjustment. Journal of Educational psychology, 93(1), 55.

Chen, J. J. L. (2005). Relation of academic support from parents, teachers, and peers to Hong Kong adolescents' academic achievement: The mediating role of academic engagement. Genetic, social, and general psychology monographs, 131(2), 77-127.

Chen, W. B., \& Gregory, A. (2009). Parental involvement as a protective factor during the transition to high school. The Journal of Educational Research, 103(1), 53-62.

Chiu, M. M., \& Xihua, Z. (2008). Family and motivation effects on mathematics achievement: Analyses of students in 41 countries. Learning and Instruction, 18(4), 321-336.

Cobb, S. (1976). Social support as a moderator of life stress. Psychosomatic medicine, 38, 300314.

Cohen, J. (2009). Transforming school climate: Educational and psychoanalytic perspectives. Schools: Studies in Education, 6, 99-103.

Cohen, J., McCabe, L., Michelli, N. M., \& Pickeral, T. (2009). School climate: Research, policy, practice, and teacher education. Teachers college record, 111(1), 180-213.

Coie, J. D., Watt, N. F., West, S. G., Hawkins, J. D., Asarnow, J. R., Markman, H. J., Ramey, S.L., Shure, M.B \& Long, B. (1993). The science of prevention: A conceptual framework and some directions for a national research program. American psychologist, 48(10), 1013.

Collaborative for Academic, Social, and Emotional Learning. (2005). Safe and sound: An educational leader's guide to evidence-based social and emotional learning (SEL) programs, Illinois Edition. Chicago, IL: Author.

Collaborative for Academic, Social, and Emotional Learning. (2015). Effective social and emotional learning programs: Middle and high school (school ed.). Chicago, IL: Author. 
Coryn, C. L., Spybrook, J. K., Evergreen, S. D., \& Blinkiewicz, M. (2009). Development and evaluation of the Social-emotional Learning Scale. Journal of Psychoeducational Assessment, 27(4), 283-295.

Cutrona, C. E., Cole, V., Colangelo, N., Assouline, S. G., \& Russell, D. W. (1994). Perceived parental social support and academic achievement: An attachment theory perspective. Journal of Personality and Social Psychology, 66(2), 369.

Dacre Pool, L., \& Qualter, P. (2012). The dimensional structure of the emotional self-efficacy scale (ESES). Australian Journal of Psychology, 64(3), 147-154.

Dirks, M. A., Treat, T. A., \& Weersing, V. R. (2007). Integrating theoretical, measurement, and intervention models of youth social competence. Clinical psychology review, 27(3), 327-347.

Domagała-Zyśk, E. (2006). The significance of adolescents' relationships with significant others and school failure. School Psychology International, 27(2), 232-247.

Dubow, E. F., \& Tisak, J. (1989). The relation between stressful life events and adjustment in elementary school children: The role of social support and social problem-solving skills. Child development, 1412-1423.

Durlak, J. A., Weissberg, R. P., Dymnicki, A. B., Taylor, R. D., \& Schellinger, K. B. (2011). The impact of enhancing students' social and emotional learning: A meta-analysis of school-based universal interventions. Child Development, 82(1), 405-432.

Dusenbury, L., Zadrazil, J., Mart, A., \& Weissberg, R. (2011). State learning standards to advance social and emotional learning. CASEL, Chicago.

Elias, M. J. (2004). Strategies to infuse social and emotional learning into academics. In J. Zins, R. Weissberg, M. Wang \& H. J. Walberg (Eds.), Building Academic Success on Social- 
Emotional Learning: What Does the Research Say? (pp. 113-134). New York: Teacher's College Press.

Elias, M. J., \& Haynes, N. M. (2008). Social competence, social support, and academic achievement in minority, low-income, urban elementary school children. School Psychology Quarterly, 23(4), 474-495.

Elias, M. J., \& Weissberg, R. P. (2000). Primary prevention: Educational approaches to enhance social and emotional learning. Journal of School Health, 70(5), 186-190.

Elias, M. J., Zins, J. E., Weissberg, K. S., Greenberg, M. T., Haynes, N. M., Kessler, R., et al. (1997). Promoting social and emotional learning: Guidelines for educators. Alexandria, VA: Association for Supervision and Curriculum Development.

Epstein, J. L., \& Connors, L. J. (1992). School and family partnerships. Practitioner, 18(4), n4.

Epstein, J. L., \& Sanders, M. G. (2002). Family, school, and community partnerships. Handbook of Parenting Volume 5 Practical Issues in Parenting, 406.

Fisher, A. J., Kramer, R. A., Grosser, R. C., Alegria, M., Bird, H. R., Bourdon, K. H., ... \& Narrow, W. E. (1997). Correlates of unmet need for mental health services by children and adolescents. Psychological Medicine, 27(05), 1145-1154.

Foster, S., Rollefson, M., Doksum, T., Noonan, D., Robinson, G., \& Teich, J. (2005). School Mental Health Services in the United States, 2002-2003. Substance Abuse and Mental Health Services Administration.

Furlong, M., Sharkey, J., Quirk, M., \& Dowdy, E. (2011). Exploring the protective and promotive effects of school connectedness on the relation between psychological health risk and problem behaviors/experiences. Journal of Educational and Developmental Psychology, 1(1), 18. 
Furman, W., \& Buhrmester, D. (1992). Age and sex differences in perceptions of networks of personal relationships. Child Development, 63(1), 103-115.

Galyon, C. E., Blondin, C. A., Yaw, J. S., Nalls, M. L., \& Williams, R. L. (2012). The relationship of academic self-efficacy to class participation and exam performance. Social Psychology of Education, 15(2), 233-249.

Gilman, R. \& Huebner, E. S. (2006). Characteristics of adolescents who report very high life satisfaction. Journal of Youth and Adolescence, 35(3), 311-319.

Goldsmith, P. A. (2004). Schools' racial mix, students' optimism, and the Black-White and LatinoWhite achievement gaps. Sociology of Education, 77(2), 121-147.

Gordon, M. S., \& Cui, M. (2012). The effect of school-specific parenting processes on academic achievement in adolescence and young adulthood. Family Relations, 61(5), 728-741.

Greenberg, M. T., Domitrovich, C., \& Bumbarger, B. (2001). The prevention of mental disorders in school-aged children: Current state of the field. Prevention \& Treatment, 4(1), 1a.

Greenberg, M. T., Weissberg, R. P., O’Brien, M. U., Zins, J. E., Fredericks, L., Resnick, H., \& Elias, M. J. (2003). Enhancing school-based prevention and youth development through coordinated social, emotional and academic learning. American Psychologist, 58, 466 - 474.

Greene, B. A., Miller, R. B., Crowson, H. M., Duke, B. L., \& Akey, K. L. (2004). Predicting high school students' cognitive engagement and achievement: Contributions of classroom perceptions and motivation. Contemporary Educational Psychology, 29(4), 462-482.

Grover, H. M., Limber, S. P., \& Boberiene, L. V. (2015). Does it matter if students experience school as a place of community?. American Journal of Orthopsychiatry, 85(6S), S79. 
Guerra, N. G., \& Bradshaw, C. P. (2008). Linking the prevention of problem behaviors and positive youth development: Core competencies for positive youth development and risk prevention. New Directions for Child and Adolescent Development, 2008(122), 1-17.

Hamre, B. K., \& Pianta, R. C. (2001). Early teacher-child relationships and the trajectory of children's school outcomes through eighth grade. Child development, 72(2), 625-638.

Harwell, M., \& LeBeau, B. (2010). Student eligibility for a free lunch as an SES measure in education research. Educational Researcher, 39(2), 120-131.

Heckman, J. J., \& Kautz, T. (2012). Hard evidence on soft skills. Labour Economics, 19(4), 451464.

Hemmeter, M. L., Ostrosky, M., \& Fox, L. (2006). Social and emotional foundations for early learning: A conceptual model for intervention. School Psychology Review, 35(4), 583-601.

Henry, K. L., Knight, K. E., \& Thornberry, T. P. (2012). School disengagement as a predictor of dropout, delinquency, and problem substance use during adolescence and early adulthood. Journal of youth and adolescence, 41(2), 156-166.

Hill, N. E., Castellino, D. R., Lansford, J. E., Nowlin, P., Dodge, K. A., Bates, J. E., \& Pettit, G. S. (2004). Parent academic involvement as related to school behavior, achievement, and aspirations: Demographic variations across adolescence. Child Development, 75(5), 14911509.

Hill, N. E., \& Taylor, L. C. (2004). Parental school involvement and children's academic achievement pragmatics and issues. Current Directions in Psychological Science, 13(4), 161164. 
Hill, N. E., \& Craft, S. A. (2003). Parent-school involvement and school performance: Mediated pathways among socioeconomically comparable African American and Euro-American families. Journal of Educational Psychology, 95(1), 74-83.

Hopson, L. M., \& Lee, E. (2011). Mitigating the effect of family poverty on academic and behavioral outcomes: The role of school climate in middle and high school. Children and Youth Services Review, 33(11), 2221-2229.

Hoffman, D. M. (2009). Reflecting on social emotional learning: A critical perspective on trends in the United States. Review of Educational Research, 79(2), 533-556.

Hoy, W. K., \& Tarter, C. J. (1997). The road to open and healthy schools: A handbook for change. Corwin Pr.

Hughes, J. N., Gleason, K. A., \& Zhang, D. (2005). Relationship influences on teachers' perceptions of academic competence in academically at-risk minority and majority first grade students. Journal of school psychology, 43(4), 303-320.

Hughes, J. N., \& Kwok, O. M. (2006). Classroom engagement mediates the effect of teacherstudent support on elementary students' peer acceptance: A prospective analysis. Journal of school psychology, 43(6), 465-480.

Isakson, K., \& Jarvis, P. (1999). The adjustment of adolescents during the transition into high school: A short-term longitudinal study. Journal of Youth and Adolescence, 28(1), 1-26.

Jeynes, W. (2012). A meta-analysis of the efficacy of different types of parental involvement programs for urban students. Urban Education, 47(4), 706-742.

Jimerson, S., Egeland, B., Sroufe, L. A., \& Carlson, B. (2000). A prospective longitudinal study of high school dropouts examining multiple predictors across development. Journal of school psychology, 38(6), 525-549. 
Jodl, K. M., Michael, A., Malanchuk, O., Eccles, J. S., \& Sameroff, A. (2001). Parents' roles in shaping early adolescents' occupational aspirations. Child Development, 72(4), 1247-1266.

Johnson, W., Brett, C. E., \& Deary, I. J. (2010). The pivotal role of education in the association between ability and social class attainment: A look across three generations. Intelligence, $38(1), 55-65$.

Johnson, D. W., \& Johnson, R. T. (1989). Cooperation and competition: Theory and research. Interaction Book Company.

Johnson, D. W., \& Johnson, R. T. (2002). Cooperative learning and social interdependence theory. In Theory and research on small groups (pp. 9-35). Springer US.

Johnson, D. W., \& Johnson, R. T. (2004). The three Cs of promoting social and emotional learning. In J.E. Zins, R. P. Weissberg, M. C. Wang, \& H. J. Walberg (Eds.), Building academic success on social and emotional learning: What does the research say? (pp. 40 - 58). New York, NY: Teachers College Press.

Jones, D. E., Greenberg, M., \& Crowley, M. (2015). Early social-emotional functioning and public health: The relationship between kindergarten social competence and future wellness. Journal Information, 105(11).

Kerpelman, J. L., Eryigit, S., \& Stephens, C. J. (2008). African American adolescents' future education orientation: Associations with self-efficacy, ethnic identity, and perceived parental support. Journal of Youth and Adolescence, 37(8), 997-1008.

Kessler, R. C., Berglund, P., Demler, O., Jin, R., Merikangas, K. R., \& Walters, E. E. (2005). Lifetime prevalence and age-of-onset distributions of DSM-IV disorders in the National Comorbidity Survey Replication. Archives of general psychiatry, 62(6), 593-602. 
Klem, A. M., \& Connell, J. P. (2004). Relationships matter: Linking teacher support to student engagement and achievement. Journal of School Health, 74(7), 262-273.

Krueger, A., Whitmore, D., Chubb, J. E., \& Loveless, T. (2002). Bridging the achievement gap. Bridging the achievement gap.

Legault, L., Green-Demers, I., \& Pelletier, L. (2006). Why do high school students lack motivation in the classroom? Toward an understanding of academic amotivation and the role of social support. Journal of educational psychology, 98(3), 567.

Lent, R. W., Brown, S. D., \& Larkin, K. C. (1986). Self-efficacy in the prediction of academic performance and perceived career options. Journal of Counseling Psychology, 33(3), 265.

Maccoby, E. E., \& Martin, J. A. (1983). Socialization in the context of the family: Parent-child interaction. Handbook of child psychology: formerly Carmichael's Manual of child psychology/Paul H. Mussen, editor.

MacNeil, A. J., Prater, D. L., \& Busch, S. (2009). The effects of school culture and climate on student achievement. International Journal of Leadership in Education, 12(1), 73-84.

Malecki, C. K., \& Demaray, M. K. (2002). Measuring perceived social support: Development of the child and adolescent social support scale (CASSS). Psychology in the Schools, 39(1), 1-18.

Malecki, C. K., Demaray, M. K., \& Elliott, S. N. (2000). The child and adolescent social support scale. DeKalb, IL: Northern Illinois University.

Malecki, C. K., \& Elliott, S. N. (1999). Adolescents' ratings of perceived social support and its importance: Validation of the Student Social Support Scale. Psychology in the Schools, 36(6), 473-483. 
Martin, A. J., \& Downson, M. (2009). Interpersonal relationships, motivation, engagement, and achievement: Yields for theory, current issues, and educational practice. Review of Educational Research, 79, $327-365$.

McCormick, M. P., O'Connor, E. E., Cappella, E., \& McClowry, S. G. (2013). Teacher-child relationships and academic achievement: A multilevel propensity score model approach. Journal of School Psychology, 51(5), 611-624.

Mo, Y., \& Singh, K. (2008). Parents' relationships and involvement: Effects on students' school engagement and performance. RMLE Online, 31(10), 1-11.

Moretti, E. (2005). Does education reduce participation in criminal activities? In H. M. Levin (Chair), Symposium on the social costs of inadequate education conducted at Teachers College. New York: Columbia University.

Mrazek, P. B., Biglan, A., \& Hawkins, J. D. (2007). Community-monitoring systems: Tracking and improving the well-being of America's children and adolescents. Society for Prevention Research.

Muris, P. (2001). A brief questionnaire for measuring self-efficacy in youths. Journal of Psychopathology and Behavioral Assessment, 23(3), 145-149.

Murray, C. (2009). Parent and teacher relationships as predictors of school engagement and functioning among low-income urban youth. The Journal of Early Adolescence.

Murray, C., \& Greenberg, M. T. (2000). Children's relationship with teachers and bonds with school an investigation of patterns and correlates in middle childhood. Journal of School Psychology, 38(5), 423-445.

Neal, J. W. and Neal, Z. P. (2013), Nested or networked? Future directions for ecological systems theory. Social Development, 22: 722-737. 
Neil, A. L., \& Christensen, H. (2007). Australian school-based prevention and early intervention programs for anxiety and depression: a systematic review. Medical Journal of Australia, 186(6), 305-308.

Nichols, J. D., \& White, J. (2001). Impact of peer networks on achievement of high school algebra students. The Journal of Educational Research, 94(5), 267-273.

Niebuhr, K. E. (1999). An empirical study of student relationships and academic achievement. Education, 119(4), 679.

Obradovic', J., Shaffer, A., \& Masten, A. S. (2012). Risk in developmental psychopathology: Progress and future directions. In L. C. Mayes \& M. Lewis (Eds.), The environment of human development: A handbook of theory and measurement (pp. 35-57). New York, NY: Cambridge University Press

Osher, D., Kidron, Y., Brackett, M., Dymnicki, A., Jones, S., \& Weissberg, R. P. (2016). Advancing the Science and Practice of Social and Emotional Learning: Looking Back and Moving Forward. Review of Research in Education, 40(1), 644-681.

Parker, J. D., Creque, R. E., Barnhart, D. L., Harris, J. I., Majeski, S. A., Wood, L. M., ... \& Hogan, M. J. (2004). Academic achievement in high school: does emotional intelligence matter?. Personality and Individual Differences, 37(7), 1321-1330.

Patrick, H., Hicks, L., \& Ryan, A. M. (1997). Relations of perceived social efficacy and social goal pursuit to self-efficacy for academic work. The Journal of Early Adolescence, 17(2), 109128.

Paulson, S. E. (1994). Relations of parenting style and parental involvement with ninth-grade students' achievement. The Journal of Early Adolescence, 14(2), 250-267. 
Payton, J. W., Wardlaw, D. M., Graczyk, P. A., Bloodworth, M. R., Tompsett, C. J., \& Weissberg, R. P. (2000). Social and emotional learning: A framework for promoting mental health and reducing risk behavior in children and youth. Journal of school health, 70(5), 179-185.

Protheroe, Nancy (2012). Social and emotional factors in student learning. Principal's Research Review 7(5), $1-7$.

Qualter, P., Gardner, K. J., Pope, D. J., Hutchinson, J. M., \& Whiteley, H. E. (2012). Ability emotional intelligence, trait emotional intelligence, and academic success in British secondary schools: A 5year longitudinal study. Learning and Individual Differences, 22(1), 83-91.

Qualter, P., Pool, L. D., Gardner, K. J., Ashley-Kot, S., Wise, A., \& Wols, A. (2015). The emotional self-efficacy scale adaptation and validation for young adolescents. Journal of Psychoeducational Assessment, 33(1), 33-45.

Ransdell, S. (2012). There's still no free lunch: Poverty as a composite of SES predicts schoollevel reading comprehension. American Behavioral Scientist, 56(7), 908-925.

Raver, C. C., \& Knitzer, J. (2002). Ready to enter: What research tells policymakers about strategies to promote social and emotional school readiness among three-and four-year-olds (No. 0205).

Raver, C. C., \& Zigler, E. F. (1997). Social competence: An untapped dimension in evaluating Head Start's success. Early Childhood Research Quarterly, 12(4), 363-385.

Ringel, J.S. \& Sturm, R. (2001) National estimates of mental health utilization and expenditures for children in 1998. Journal of Behavioral Health and Research, 28, 319 - 333.

Robers, S., Kemp, J., \& Truman, J. (2013). Indicators of School Crime and Safety: 2012. NCES 2013-036/NCJ 241446. National Center for Education Statistics. 
Rosenfeld, L. B., Richman, J. M., \& Bowen, G. L. (2000). Social support networks and school outcomes: The centrality of the teacher. Child and Adolescent Social Work Journal, 17(3), 205-226.

Rubin, K. H., Bukowski, W. M., \& Parker, J. G. (2006). Peer interactions, relationships, and groups. Handbook of child psychology.

Sage, N. A., \& Kindermann, T. A. (1999). Peer networks, behavior contingencies, and children's engagement in the classroom. Merrill-Palmer Quarterly (1982-), 143-171.

Salmela-Aro, K., \& Tynkkynen, L. (2010). Trajectories of life satisfaction across the transition to post-compulsory education: do adolescents follow different pathways?. Journal of youth and adolescence, 39(8), 870-881.

Schunk, D. H., Pintrick, P. R. \& Meece, J. L. (2010). Motivation in education. Theory, research and application. Upper Saddle River, NJ: Pearson/Merrill Prentice Hall.

Sedlack, M. W., Wheeler, C. W., Pullin D. C., Cusick, P. S. (1996). Selling students short: Classroom bargains and academic reform in the American school. New York, NY: Teachers College Press.

Seginer, R. (2006). Parents' educational involvement: A developmental ecology perspective. Parenting: Science and Practice, 6(1), 1-48.

Sirin, S. R. (2005). Socioeconomic status and academic achievement: A meta-analytic review of research. Review of Educational Research, 75(3), 417-453.

Slominski, L., Sameroff, A., Rosenblum, K., \& Kasser, T. (2011). Longitudinal predictors of adult socioeconomic attainment: The roles of socioeconomic status, academic competence, and mental health. Development and Psychopathology, 23, 315-324. 
Sklad, M., Diekstra, R., Ritter, M. D., Ben, J., \& Gravesteijn, C. (2012). Effectiveness of schoolbased universal social, emotional, and behavioral programs: Do they enhance students' development in the area of skill, behavior, and adjustment? Psychology in the Schools, 49(9), 892-909.

Song, J., Bong, M., Lee, K., \& Kim, S. I. (2015). Longitudinal investigation into the role of perceived social support in adolescents' academic motivation and achievement. Journal of Educational Psychology, 107(3), 821.

Steinberg, L. (1991). Adolescent transitions and alcohol and other drug use prevention. Preventing adolescent drug use: From theory to practice, 13-51.

Stewart, E. B. (2008). School structural characteristics, student effort, peer associations, and parental involvement the influence of school-and individual-level factors on academic achievement. Education and urban society, 40(2), 179-204.

Stewart, T., \& Suldo, S. (2011). Relationships between social support sources and early adolescents' mental health: The moderating effect of student achievement level. Psychology in the Schools, 48(10), 1016-1033.

Strayhorn, T. L. (2010). The role of schools, families, and psychological variables on math achievement of black high school students. The High School Journal, 93(4), 177-194.

Strenze, T. (2007). Intelligence and socioeconomic success: A meta-analytic review of longitudinal research. Intelligence, 35(5), 401-426.

Suldo, S., Friedrich, A. A., White, T., Farmer, J., Minch, D., \& Michalowski, J. (2009). Teacher support and adolescents' subjective well-being: A mixed-methods investigation. School Psychology Review, 38, 67-85. 
Tennant, J. E., Demaray, M. K., Malecki, C. K., Terry, M. N., Clary, M., \& Elzinga, N. (2015). Students' ratings of teacher support and academic and social-emotional well-being. School psychology quarterly, 30(4), 494.

Thapa, A., Cohen, J., Guffey, S., \& Higgins-D’Alessandro, A. (2013). A review of school climate research. Review of Educational Research, 83(3), 357-385.

Tolan, P. H., \& Dodge, K. A. (2005). Children's Mental Health as a Primary Care and Concern: A System for Comprehensive Support and Service. The American Psychologist, 60(6), 601614.

U.S. Department of Education, Institute of Education Sciences, National Center for Education Statistics (2015).

Van Ewijk, R., \& Sleegers, P. (2010). The effect of peer socioeconomic status on student achievement: A meta-analysis. Educational Research Review, 5(2), 134-150.

Vitoroulis, I., Schneider, B. H., Vasquez, C. C., de Toro, M. D. P. S., \& Gonzáles, Y. S. (2012). Perceived parental and peer support in relation to Canadian, Cuban, and Spanish adolescents' valuing of academics and intrinsic academic motivation. Journal of Cross-Cultural Psychology, 43(5), 704-722.

Waldfogel, J., Garfinkel, I., \& Kelly, B. (2005). Public assistance programs: How much could be saved with improved education? In H. M. Levin (Chair), Symposium on the social costs of inadequate education conducted at Teachers College. New York: Columbia University.

Wang, M. T., \& Degol, J. L. (2016). School climate: A review of the construct, measurement, and impact on student outcomes. Educational Psychology Review, 28(2), 315-352. 
Wang, M. C., Haertel, G. D. and Walberg, H. J. (1997) Learning influences, in: H. J. Walberg and G. D. Haertel (eds) Psychology and Educational Practice (Berkley, CA: McCuthan), pp. $199-211$.

Wang, M. T., \& Sheikh-Khalil, S. (2014). Does parental involvement matter for student achievement and mental health in high school?. Child Development, 85(2), 610-625.

Waxman, H. C., Huang, S. Y. L., Anderson, L., \& Weinstein, T. (1997). Classroom process differences in inner-city elementary schools. The Journal of Educational Research, 91(1), 4959.

Weissberg, R. P., Durlak, J. A., Domitrovich, C. E., \& Gullotta, T. P. (2015). Social and emotional learning: Past, present, and future. Handbook of social and emotional learning: Research and practice, 3-19.

Weissberg, R. P., Walberg, H. J., O’Brien, M. U., \& Kuster, C. B. (Eds.). (2003). Long-term trends in the well-being of children and youth. Washington, DC: Child Welfare League of America Press.

Wentzel, K. R., Barry, C. M., \& Caldwell, K. A. (2004). Friendships in Middle School: Influences on Motivation and School Adjustment. Journal of Educational Psychology, 96(2), 195.

Wentzel, K. R., Battle, A., Russell, S. L., \& Looney, L. B. (2010). Social supports from teachers and peers as predictors of academic and social motivation. Contemporary Educational Psychology, 35(3), 193-202.

Wentzel, K. R., \& Caldwell, K. (1997). Friendships, peer acceptance, and group membership: Realtions to academic achievement in middle school. Child Development, 68(6), 1198-1209.

Wheeler, V. A., \& Ladd, G. W. (1982). Assessment of children's self-efficacy for social interactions with peers. Developmental Psychology, 18(6), 795. 
Whipple, S. S., Evans, G. W., Barry, R. L., \& Maxwell, L. E. (2010). An ecological perspective on cumulative school and neighborhood risk factors related to achievement. Journal of Applied Developmental Psychology, 31(6), 422-427.

Zimmerman, B. J. (1995). Self-efficacy and educational development. Self-efficacy in changing societies, 202-231.

Zimmerman, B. J. (2000). Self-efficacy: An essential motive to learn. Contemporary educational psychology, 25(1), 82-91.

Zins, J. E., \& Elias, M. J. (2006). Social and emotional learning. In G. G. Bear \& K. M. Minke (Eds.), Children's needs III: Development, prevention, and intervention (pp. 1-13). Bethesda, MD: National Association of School Psychologists.

Zins, J. E., Bloodworth, M. R., Weissberg, R. P., \& Walberg, H. J. (2004). The scientific base linking social and emotional learning to school success. Building academic success on social and emotional learning: What does the research say, 3-22.

Zins, J. E., Weissberg, R. P., Wang, M. C., \& Walberg, H. J. (Eds.) (2004). Building academic success on social and emotional learning: What does the research say? NY: Teachers College Press. 


\begin{abstract}
ADOLESCENT ACHEIVEMENT: RELATIVE CONTRIBUTIONS OF SOCIAL EMOTIONAL LEARNING, SELF-EFFICACY AND MICROSYSTEM SUPPORTS
\end{abstract}

by

\title{
MEGHAN ELIZABETH FAIRLESS
}

May 2017

Advisor: Dr. Cheryl Somers, Ph.D.

Major: Educational Psychology

Degree: Doctor of Philosophy

The purpose of the current study was to examine the roles of select intrapersonal and microsystem factors in high school adolescents' academic achievement. The selected combination of factors was hypothesized to be unique in their ability to explain greater proportions of variance in academic achievement in adolescents. A specific model through an ecological framework was proposed. Participants included 379 high school students (176 males, 193 females) from a midwestern, suburban high school that enrolls approximately 1,500 students. A variety of variables emerged as significant predictors of academic achievement, with social emotional learning, selfefficacy, socio-economic status, parental involvement, peer support, and teacher support all explaining significant proportions of variance in achievement, and some to stronger degrees than others This lends support to the notion that learning is shaped by a myriad ecological factors. These findings are discussed with regard to their usefulness in understanding ways in which to target each of the investigated variables to ultimately increase academic achievement in adolescents. 


\title{
AUTOBIOGRAPHICAL STATEMENT
}

\author{
Meghan Elizabeth Fairless
}

\section{EDUCATION}

2017

Doctor of Philosophy (PhD), Wayne State University - Detroit, MI Major: Educational Psychology

2013

Masters of Science (MS) - Philadelphia College of Osteopathic Medicine, Philadelphia, PA

Major: School Psychology

2008

Bachelor of Science (BS) - University of Michigan - Ann Arbor, MI Major: Brain, Behavior and Cognitive Science

\section{PROFESSIONAL EXPERIENCE}

01/16 - Present Clinical Intern, General Pediatric and Adolescent Medicine Clinic Children's Hospital of Michigan - Detroit, MI.

Supervisor: Dr. Douglas Barnett, Ph.D., L.P.

09/15 - Present School Psychologist, Waterford School District - Waterford, MI

08/14 - 08/16 Teaching Assistant, Wayne State University - Detroit, MI Psychological Evaluation III, Psychological Evaluation IV, Psychotherapy: Children \& Adolescents

01/15 - 05/15 School Psychology Intern, Ferndale Public Schools - Ferndale, MI Supervisor: Amy Hawtin, M.A. School Psychology

09/14 - 12/14 Clinical Intern, General Pediatric and Adolescent Medicine Clinic Children's Hospital of Michigan - Detroit, MI.

Supervisor: Dr. Douglas Barnett, Ph.D., L.P.

\section{LICENSURE AND CERTIFICATION}

2016

2015

\section{SCHOLARSHIPS}

$2016-2017$

2015-2016
Michigan: School Psychology Full Certificate

Michigan: School Psychologist Preliminary Certificate
Graduate Professional Scholarship Award

Graduate Professional Scholarship Award 